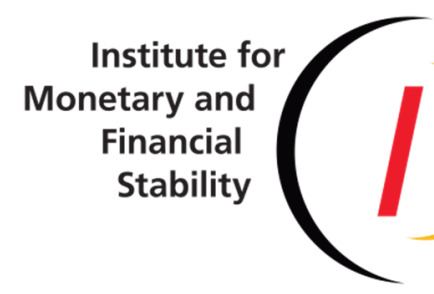

MATTHEW AGARWALA, MATT BURKE, PATRYCJA KLUSAK, MORITZ KRAEMER, KAMIAR MOHADDES

Rising Temperatures, Falling Ratings:

The Effect of Climate Change on Sovereign Creditworthiness

Institute for Monetary and Financial Stability

GOETHE UNIVERSITY FRANKFURT

WoRKING PAPER SERIES No. 158 (2021) 
This Working Paper is issued under the auspices of the Institute for Monetary and Financial Stability (IMFS). Any opinions expressed here are those of the author(s) and not those of the IMFS. Research disseminated by the IMFS may include views on policy, but the IMFS itself takes no institutional policy positions.

The IMFS aims at raising public awareness of the importance of monetary and financial stability. Its main objective is the implementation of the "Project Monetary and Financial Stability" that is supported by the Foundation of Monetary and Financial Stability. The foundation was established on January 1, 2002 by federal law. Its endowment funds come from the sale of 1 DM gold coins in 2001 that were issued at the occasion of the euro cash introduction in memory of the D-Mark.

The IMFS Working Papers often represent preliminary or incomplete work, circulated to encourage discussion and comment. Citation and use of such a paper should take account of its provisional character.

\section{Institute for Monetary and Financial Stability}

Goethe University Frankfurt

House of Finance

Theodor-W.-Adorno-Platz 3

D-60629 Frankfurt am Main

www.imfs-frankfurt.de | info@imfs-frankfurt.de 


\title{
Rising Temperatures, Falling Ratings: The Effect of Climate Change on Sovereign Creditworthiness*
}

\author{
Patrycja Klusak $^{\text {ab }}$, Matthew Agarwala ${ }^{\text {bc }}$, Matt Burke ${ }^{a b}$, \\ Moritz Kraemer ${ }^{\mathrm{de}}$, and Kamiar Mohaddes ${ }^{\mathrm{f}}$ \\ ${ }^{\text {a }}$ University of East Anglia, UK \\ ${ }^{\mathrm{b}}$ Bennett Institute for Public Policy, University of Cambridge, UK \\ ${ }^{\mathrm{c}}$ Centre for Social and Economic Research on the Global Environment, UEA, UK \\ ${ }^{\mathrm{d}}$ Centre for Sustainable Finance, SOAS, UK \& ${ }^{\mathrm{e}}$ Goethe-University, Frankfurt, Germany \\ f Judge Business School \& King's College, University of Cambridge, UK
}

\begin{abstract}
March 14 ${ }^{\text {th }}, 2021$
Abstract

Enthusiasm for 'greening the financial system' is welcome, but a fundamental challenge remains: financial decision makers lack the necessary information. It is not enough to know that climate change is bad. Markets need credible, digestible information on how climate change translates into material risks. To bridge the gap between climate science and real-world financial indicators, we simulate the effect of climate change on sovereign credit ratings for 108 countries, creating the world's first climate-adjusted sovereign credit rating. Under various warming scenarios, we find evidence of climate-induced sovereign downgrades as early as 2030, increasing in intensity and across more countries over the century. We find strong evidence that stringent climate policy consistent with limiting warming to below $2{ }^{\circ} \mathrm{C}$, honouring the Paris Climate Agreement, and following RCP 2.6 could nearly eliminate the effect of climate change on ratings. In contrast, under higher emissions scenarios (i.e., RCP 8.5), 63 sovereigns experience climate-induced downgrades by 2030, with an average reduction of 1.02 notches, rising to 80 sovereigns facing an average downgrade of 2.48 notches by 2100 . We calculate the effect of climate-induced sovereign downgrades on the cost of corporate and sovereign debt. Across the sample, climate change could increase the annual interest payments on sovereign debt by US\$ $22-33$ billion under RCP 2.6 , rising to US\$ $137-$ 205 billion under RCP 8.5 . The additional cost to corporates is US\$ 7.2-12.6 billion under RCP 2.6, and US\$ 35.8-62.6 billion under RCP 8.5.
\end{abstract}

Keywords: Sovereign credit rating, climate change, counterfactual analysis, climate-economy models, corporate debt, sovereign debt.

\footnotetext{
* We are grateful for helpful comments and suggestions from Franklin Allen, Kevin Aretz, Diane Coyle, Naoki Funada, Stephany Griffith-Jones, Zeina Hasna, Raphael Markellos, Ellen Quigley, Nick Robbins, Nina Seega, Richard Tol, Uli Volz, Dimitri Zenghelis, and colleagues across the INSPIRE network. This work is possible due to funding from INSPIRE. Matthew Agarwala acknowledges financial support for the Bennett Institute Wealth Economy Programme from LetterOne.

${ }^{\dagger}$ Corresponding author. E-mail address: mka30@cam.ac.uk
} 


\section{Introduction}

Climate change is "the biggest market failure the world has seen" (Stern 2008), with wideranging implications for stability - financial, economic, political, social, and environmental. Leading climate-economy models estimate economic losses from climate change of between $2 \%$ and $22 \%$ of gross world product by 2100 (Burke et al., 2015; Dell et al., 2014 and Kahn et al, 2019). Beyond impacts on aggregate output, the environmental, social and policy consequences of climate change will directly impact firms, investors, and regulators. Possible transmission pathways include physical damages from extreme weather events, consumer movements (including boycotts, protests, in reputational risks), transition risks (e.g., from regulations and asset stranding), and litigation risks (e.g., lawsuits over environmental damages). Dietz et al. (2016) estimate that the 'climate value at risk' of global financial assets amounts to US \$2.5 trillion. Financial markets face growing pressure to factor these climate impacts into decision making and to mobilise trillions of dollars of capital in pursuit of a Just Transition towards a low carbon future (Fiedler et al., 2021). Whilst enthusiasm for 'greening the financial system' is welcome, a fundamental challenge remains: investors and businesses lack the necessary information.

To green the financial system, it is not enough to know that climate change is bad. Firms, investors, financial institutions, and regulators need scientifically credible information on how climate change translates into material financial risks, how to price those risks, and how to manage them. Growing demand for climate risk disclosures comes from private investors, activist shareholders, universal owners, public regulators, treasuries and central banks (Deutsche Bundesbank 2019). Investor-led demand for climate risk disclosures has sparked a rapid expansion of the Environmental, Social, and Corporate Governance (ESG) ratings market, which by some estimates may reach $\$ 1$ billion in 2021 , with approximately $\$ 30$ trillion, or one-third of all professionally managed assets now subject to ESG criteria (Opimas 2020; Howard-Grenville 2021). Regulator-led demand for climate disclosures includes the development of the Task Force on Climate-related Financial Disclosures (TCFD) to improve risk assessments, support better informed capital allocation decisions, and improve short-, medium-, and long-term strategic planning (TCFD 2017). Globally, more than 1,340 companies with a market capitalization of $\$ 12.6$ trillion and financial institutions responsible for assets of $\$ 150$ trillion have expressed support for the TCFD (TCFD 2020). 
However, the credibility and usefulness of existing climate disclosures is mixed (Mathiesen 2018; Siew 2015). A chief concern is the lack of scientific foundations in climate risk disclosures. Climate models typically operate at the global or national scale, and assess changes in temperature and precipitation over decades or centuries. Translating these projections into material risk assessments on the spatial and temporal scale needed for business and investment decisions remains a challenge (Fielder et al., 2021). Beyond the lack of scientific underpinnings, further limitations include a narrow focus on firm behaviour to the exclusion of crucial systemic and macroeconomic context, short-term assessments that fuel the "tragedy of the horizon" (Carney 2015), and the incomparability of disclosures from different firms and ESG ratings methods (Fiedler et al., 2021; Mathiesen 2018). The result is an overall failure to translate climate science into credible metrics for conveying risks to financial decision makers.

We contribute to closing the gap between climate science and real-world financial indicators. Specifically, we simulate the effect of climate change on sovereign credit ratings for 108 countries under three different warming scenarios, reporting results for the years 2030, 2050, 2070, and 2100. The conceptual framework described in Figure 1 outlines our process for 'softlinking' climate science with climate economics, leading sovereign credit ratings methods, and existing evidence on the effects of sovereign downgrades on the cost of public and corporate debt. Our goal is to remain as close as possible to climate science, economics, and real-world practice in the field of sovereign credit ratings. To the best of our knowledge, we are the first to simulate the effect of future climate change on sovereign credit ratings, and our approach enables us to evaluate these impacts under various policy and warming scenarios. ${ }^{1}$

In Figure 1, blue boxes (top row) represent the status quo in three domains: climate science, climate-economics, and sovereign credit ratings. Climate science projects changes in temperature and precipitation. Climate economics translates these into impacts on output and growth (white box). However, a significant gap remains between climate-adjusted GDP estimates and sovereign ratings. The green boxes and arrows represent our novel approach to closing this gap. ${ }^{2}$ First, we develop a random forest machine learning model to predict sovereign credit ratings, training it on sovereign ratings issued by S\&P (2015-2020) to

\footnotetext{
${ }^{1}$ S\&P $(2015 a, b)$ represent the first investigations into the effect of extreme weather and natural disasters on ratings. However, they only include direct damage to property and infrastructure resulting from 1-in-250 year natural disastsers. For an extended review of literature see Appendix A.

${ }^{2}$ Climate-economy model literature is vast. See extended literature review in Appendix A.
} 
maximise its predictive accuracy. Second, we combine climate economic models and S\&P's own natural disaster risk assessments to develop a set of climate-adjusted macroeconomic data (government performance variables) to feed the ratings prediction model created in step 1. We feed our model with climate-adjusted macroeconomic inputs under a range of policy and warming scenarios to simulate the effect of climate change on sovereign ratings, reporting results for 2030,2050, 2070, and $2100 .^{3}$ Finally, using existing research on the effect of sovereign downgrades on yields, we calculate the additional cost of corporate and sovereign capital due to climate-induced sovereign downgrades (purple).

\section{Figure 1. Conceptual Framework: Bridging the gap between climate science and financial indicators}

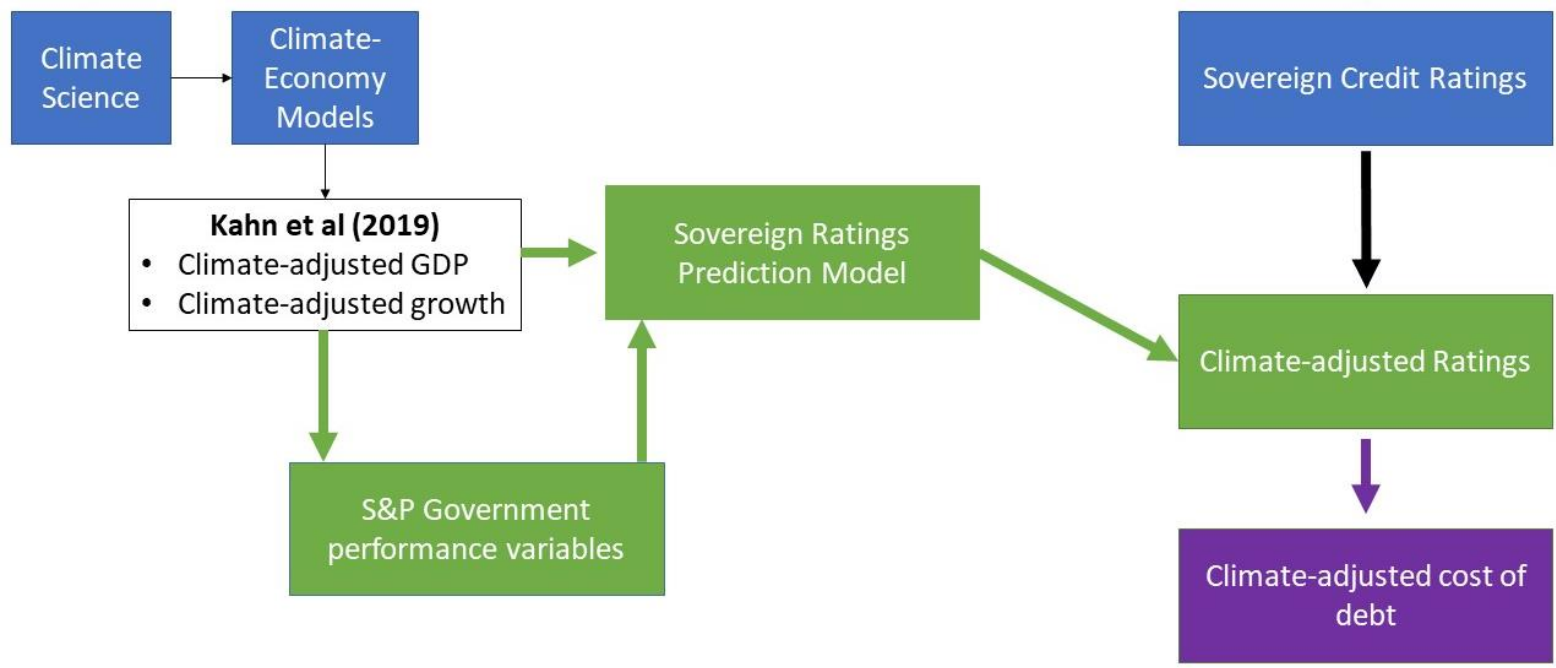

We focus on sovereign ratings for several reasons. First, they are readily interpretable and familiar indicators creditworthiness, already used by investors, portfolio managers, financial institutions and regulators in a range of decision contexts. For instance, ratings are 'hardwired' into decisions over which securities investors can hold (e.g., institutional investors may be committed by their charter not to hold debt below a certain rating (Fuchs \& Gehring 2017)). Similarly, under Basel II rules, ratings directly affect the capital requirements ${ }^{4}$ of banks and insurance companies (Almeida et al., 2017). Moreover, approximately US\$ 66 trillion, global sovereign debt accounts for a large share of total assets under management (PRI 2019). As

\footnotetext{
${ }^{3}$ Results for other years available on request

${ }^{4}$ Basel II 'hardwires' ratings into the capital requirements imposed on banks and insurance companies holding specific sovereigns or firms. The rating bins on sovereign claims and their corresponding risk weights are as follows: $\mathrm{AAA}$ to $\mathrm{AA}-(0 \%), \mathrm{A}+$ to $\mathrm{A}-(20 \%), \mathrm{BBB}+$ to $\mathrm{BBB}-(50 \%), \mathrm{BB}+$ to $\mathrm{B}-(100 \%)$, and below $\mathrm{B}-(150 \%)$ (Almeida et al., 2017).
} 
measures of the creditworthiness of this debt, sovereign ratings act as 'gatekeepers' to global markets, significantly influencing the cost and allocation of capital across countries (Cornaggia et al., 2017).

Sovereign downgrades increase the cost of both public and private debt, influencing overall economic performance and with potentially significant implications for business across all sectors (Chen et al., 2016). If the economic effects of climate change reduce sovereign creditworthiness, there could be indirect impacts on other asset classes. One potential mechanism is the "sovereign ceiling effect," ${ }^{5}$ whereby sovereign ratings implicitly place an upper bound on ratings in other asset classes (Adelino \& Ferrera 2016; Almeida et al., 2017; Borensztein et al., 2013). A second and closely related mechanism is the observed 'sovereign spill-over effect', whereby sovereign downgrades are quickly followed by downgrades in other asset classes (Augustin et al., 2018; Baum et al., 2016; Gennaioli et al., 2014). Because both the ceiling and spillover effects are more pronounced for firms and financial institutions whose ratings are closest to the sovereign's, any climate-induced downgrades are likely to have a greater impact on the highest rated firms.

A further motivation for focusing on sovereign ratings is the observation that climate change does not just affect firms individually, it affects countries and economies systemically. Narrow, firm-level assessments that ignore broader climate impacts are necessarily incomplete. For instance, major floods, storms, and fires have impacts across sectors rather than just hitting individual firms. Combined, the sovereign ceiling, spillovers, size of the sovereign bond market, and the indiscriminate nature of climate change means no corporate climate risk assessment is complete without also considering the effect climate on sovereigns. Finally, because sovereign ratings impact bond yields (i.e., the cost of public borrowing), understanding how they might be affected by climate change is central to long-term fiscal sustainability.

\footnotetext{
${ }^{5}$ For example, following a sovereign downgrade of Italy on the 28th April 2020, Fitch downgraded four Italian banks: UniCredit S.p.A.'s, Intesa Sanpaolo's (IntesaSP), Mediobanca S.p.A.'s, and Unione di Banche Italiane S.p.A.'s (UBI). https://www.fitchratings.com/research/structured-finance/covered-bonds/fitch-downgrades-fouritalian-banks-following-sovereign-downgrade-12-05-2020. Similarly, Moody's downgraded 58 sub-sovereign entities after UK's sovereign action 16th October 2020.

https://www.moodys.com/touupdated.aspx?isAnnual=true \&lang=en \&cy=global $\&$ ru= $\% 2$ fresearch $\% 2 \mathrm{fMoodys}-$ has-taken-rating-actions-on-58-sub-sovereign-entities--PR 434579
} 
Our results document three key findings. First, we show that under various warming scenarios, climate change could induce sovereign downgrades as early as 2030, with larger downgrades across more countries to 2100 . For instance, in absence of climate policies (i.e., RCP $8.5^{6}$ scenario), 63 sovereigns experience downgrades of approximately 1.02 notches by 2030, rising to 80 sovereigns facing a downgrade of 2.48 notches by 2100 . Second, our data strongly suggests that stringent climate policy consistent with the Paris Climate Agreement will result in minimal changes to the current ratings profile. We find that an average reduction is sovereign rating of 0.65 notches remains unchanged over time between 2030-2100. The additional costs to sovereign debt - best interpreted as increases in annual interest payments due to climateinduced sovereign downgrades - in our sample is US\$22-33 billion under RCP 2.6, rising to US\$ 137-205 billion under RCP 8.5. The additional costs to corporates reach US\$ 7.2-12.6 billion under RCP 2.6, and US\$ 35.8-62.6 billion under RCP 8.5. This suggests that early investments in climate mitigation and adaptation can ultimately improve long-run fiscal sustainability and reduce corporate costs of debt. We find qualitatively similar results using two independent climate-economy models; Burke et al. (2015) and Kahn et al. (2019). Results are robust to changing the time series of ratings used to train the prediction model, restricting the model to only those sovereigns with investment grade ratings, and varying assumptions about the degree of temperature volatility within the baseline climate-economic model.

These results are of interest to finance ministries and central banks, regulators (e.g., ESMA and the SEC), banks, insurers, and institutional investors. Climate-induced sovereign downgrades provide a direct and immediate financial incentive for sovereigns to pursue climate-smart investments, (e.g., boosting resilience and adaptive capacity) to improve their current rating and reduce the cost of borrowing. The research is timely, as governments seek to balance fiscal stimulus following the Covid-19 pandemic against the need to manage the public finances in the long run. That public investment in low-carbon climate resilient infrastructure presents an attractive long-run growth opportunity is firmly established (Hepburn et al., 2020; Zenghelis et al., 2020). Our results add further support by demonstrating that earlier action improves fiscal positions through two channels: (i) reducing the cost of corporate debt, thereby enhancing

\footnotetext{
${ }^{6}$ RCPs are Representative Concentration Pathways and describe different potential scenarios of future emissions trends. RCP 2.6 is the 'stringent climate policy' scenario and is most consistent with limiting warming to below $2{ }^{\circ} \mathrm{C}$. RCP 8.5 is the high emissions scenario and is more consistent with a $5^{\circ} \mathrm{C}$ warming world. See extended literature review, Appendix A.
} 
competitiveness, and (ii) reducing future interest rates on sovereign debt, thereby maintaining fiscal operating space and reducing future tax burdens.

Our results are of central importance to the regulation of CRAs and development of ESG standards. Although the European Securities and Markets Authority (ESMA, which regulates credit ratings agencies (CRAs) in Europe) has called for greater transparency and disclosure around ESG factors they have refrained from introducing formal requirements (ESMA 2019). Existing climate disclosures and ESG ratings remain largely voluntary and are not standardised. CRAs recognise that climate and environmental factors "could have significant implications for sovereign ratings in the decades to come... [although they] pose a negligible direct risk to sovereign ratings in advanced economies for now, on average, ratings on many emerging sovereigns (specifically those in the Caribbean or Southeast Asia) will likely come under significant additional pressure" (S\&P 2018). One potential obstacle is a lack of credible methods for assessing the impact of climate on creditworthiness (Buhr et al., 2018). Our research represents a first step in providing such a method.

The remainder of this paper is as follows. Section 2 describes data and methodology. Section 3 provides empirical results of climate-adjusted sovereign credit ratings. Section 4 discusses additional cost sovereign and corporate borrowing due to climate-induced downgrades. Finally, Section 5 offers some concluding remarks.

\section{Data and methodology}

\subsection{Rating data}

Our sample consists of 1385 annual long-term foreign-currency sovereign ratings for 108 countries, issued by S\&P between 2004 and 2020, obtained from S\&P Ratings Direct database. Alphabetical ratings are translated into a 20 -notch scale widely used in the literature (Correa et al., 2014; see Table B.1). Although several agencies issue sovereign ratings, we use S\&P's because they have the widest country coverage over the assessment period and their ratings actions have the strongest own-country stock market impact (Almeida et al., 2017; Brooks et al., 2004; Kaminsky \& Schmukler 2002). 


\subsection{Macroeconomic data}

Our ratings prediction model is parsimonious, incorporating just six macroeconomic indicators. ${ }^{7}$ This approach is motivated by a desire to avoid overfitting, and most importantly, to ensure our model inputs remain as close as possible to the underlying climate science and economic models. Our baseline climate-economy model (Kahn et al., 2019) provides estimates of climate-adjusted real GDP growth rates and levels up to 2100. Table 1 presents our determining factors and highlights a range of cross-sectional descriptive statistics. Data comes from S\&P Ratings Direct Sovereign Risk Indicators (SRIs). Countries in the sample display a wide range of income levels, growth rates, and macroeconomic performance indicators.

\section{Table 1. Summary Statistics}

\begin{tabular}{l|l|l|l|l}
\hline Variable & Mean & St. Dev. & Min & Max \\
\hline Log GDP per capita (US \$) & 8.98 & 0.19 & 8.47 & 9.20 \\
Real GDP Growth & 0.78 & 2.77 & -0.09 & 11.19 \\
Net General Government Debt/GDP & 29.87 & 6.13 & 19.09 & 37.94 \\
Narrow Net External Debt/CARs & 51.96 & 11.89 & 28.91 & 66.58 \\
Current Account Balance/GDP & -1.42 & 1.01 & -3.64 & 0.81 \\
General Government Balance/GDP & -2.01 & 1.38 & -4.36 & 0.16 \\
\hline
\end{tabular}

Notes: Table 1 presents summary statistics for the natural logarithm of nominal GDP per capita in US \$ (Log GDP per capita (US\$)), the annual nominal growth rate (GDP Growth), net general government debt/GDP, narrow net external debt/current account receipts (CARs), current account balance/GDP, and general government balance/GDP. Data sample covers period between 2004 and 2020.

Variable selection is based on several factors: relevance for predicting ratings, the availability and quality of scientific evidence describing how they respond to climate change, and country coverage. Our commitment to climate-science underpinnings entails a trade-off: we are unable to include some important determinants of ratings (e.g., political stability and government transparency, see Table 2) because we do not have credible science-based descriptions of how they vary with climate. The method is readily extendable when such information becomes available. Furthermore, we provide evidence that these variables lose predictive importance as we move up the ratings scale, instilling further confidence in our results because the impact of climate on ratings is most substantial for highly rated sovereigns.

\footnotetext{
${ }^{7}$ For example, De Moor et al. (2018) and Ozturk et al. (2016) employ 23 and 16 variables to predict ratings. See the literature review in Appendix A.
} 


\subsection{Methods}

We create a parsimonious, six-variable model to reconstruct sovereign credit ratings based on S\&P's published methodology. ${ }^{8}$ The twin objectives are (i) to remain as close as possible to S\&P's ratings method to ensure good predictive capacity, and (ii) maintain the greatest possible scope for incorporating science-based climate-adjusted macroeconomic variables. ${ }^{9}$

Two of these (climate-adjusted GDP and its growth rate) come directly from climate-economic models (Kahn et al., 2019; Burke et al., 2015). Beyond GDP, sovereign ratings include a range of government performance indicators including net general government debt/GDP, narrow net external debt/current account receipts, current account balance/GDP, and general government balance/GDP. To construct climate-adjusted versions of the four government performance variables in our model, we construct statistical models based on data from S\&P's own assessments (see SM, Appendix B for details). For example, S\&P (2015b) produce estimates of the effect of various climate and natural disasters on our set of government performance indicators presented in column 1 of Table 1.

Finally, we feed our newly created climate-adjusted macroeconomic indicators to our sovereign ratings model to simulate the effect of climate on ratings. For comparability with the literature and to demonstrate the effect of strict climate policies that are consistent with meeting the Paris Agreement, we present results under four warming scenarios: RCP 2.6, RCP 8.5, and both of these, but allowing the variability of temperature around its long-run average to rise with temperature.

\subsubsection{Reconstructing sovereign credit ratings}

We develop a two-step strategy to simulate the effect of climate change on sovereign ratings. Using S\&P's sovereign rating method as a template, step one constructs a sovereign ratings prediction model using supervised machine learning methodologies (Breiman 2001). Step two

\footnotetext{
${ }^{8}$ Sovereign credit ratings incorporate a wide range of objective macroeconomic data and subjective assessments by ratings agencies. Although the science, economics, and politics of climate change are widely studied, we do not have a reliable source of information on how climate change will impact every variable included in the sovereign ratings methodology.

${ }^{9}$ Due to the nature of macroeconometric climate models, our results focus primarily on economic losses arising from physical impacts of climate change. That is, we do not capture transition or litigation risks, including the possibility of climate refugees, civil unrest, or political instability. However, our approach can be readily extended to incorporate these impacts when credible quantitative estimates are available. As such, our results may be considered lower-bound estimates of the effect of climate change on sovereign ratings.
} 
identifies or constructs climate-adjusted versions of macroeconomic performance indicators to feed the prediction model from Step 1. The two most prominent climate-adjusted indicators are log per capita GDP and real GDP growth, which we take directly from Kahn et al. (2019) under two warming scenarios, RCP 2.6 and RCP 8.5. The remaining four are termed the 'government performance indicators' and are identified by S\&P as important inputs into sovereign ratings. These include: net general government debt/GDP, narrow net external debt/current account receipts (CARs), current account balance/GDP, and general government balance/GDP.

Traditional approaches to modelling credit ratings rely on parametric estimations (such as ordered response models or OLS; see for example, Cantor \& Packer 1996; Afonso et al., 2009; 2011; Baghai et al., 2016). However, due to the non-linearity of ratings and their distributional properties, and to address multicollinearity, researchers have considered non-parametric approaches to model sovereign ratings (Bennell et al., 2006; De Moor et al., 2018; Fioramanti, 2008; Markellos et al., 2016; Ozturk et al., 2016). The central benefits associated with these approaches are much better handling of non-linear outcomes in the data (Markellos et al., 2016) and the potential for superior fit (De Moor, 2018). Because sovereign ratings may be subject to thresholds in country-level predictors, such as GDP per capita (S\&P 2017), methods capable of handling non-linearities are essential.

Random forest algorithms are the primary machine learning technique in the application of credit rating prediction (Ozturk et al., 2016; De Moor et al., 2018). Decision tree algorithms operate by constructing a series of nodes (see SM, Appendix A, Figure A.2). At each node the algorithm selects the feature which provides the best split of the data. Once the data has been split on the first feature, it then attempts to split the data again such that the subsequent splits are as different from the previous split as possible, but as similar to each other as possible. This process continues until the data can no longer be split on the features provided.

Random forest algorithms can be thought of as extensions of decision trees. However, whereas decision tree algorithms can be highly sensitive to the data on which they have been trained, random forests reduce this sensitivity by enabling each tree within the forest to be trained upon a randomly selected sub-sample of the data, with replacement. Moreover, in an ordinary decision tree process, the algorithm selects the feature (from all available features) which provides the best split. A random forest algorithm enables the tree to select from only a random subset of features. The intuition behind each of these two modifications is that the prediction 
made by a forest is an average of the decision made by each tree, and as a consequence is much more reliable and robust as a collection.

\subsubsection{Random forest estimation, variable importance, and partial plots}

A key advantage of using machine-learning approaches is their ability to model non-linearities. Figure 2 shows the partial effect of increases in standardised GDP per capita and the growth rate on the sovereign credit rating. The left panel demonstrates that as ln GDP per capita (US\$) increases, the sovereign meets the threshold criteria for increasing rating scores. Furthermore, this panel demonstrates that GDP per capita has various empirical limitations with regards to the ratings it will impact. For instance, the graph suggests that at a certain point, ln GDP per capita (US\$) can continue to decrease with no resulting impact on the rating. This may partially explain the effect of the estimations on poorer countries observed in the previous sections. Other variables may be more important at predicting ratings at the lower end of the scale. The second panel to the right demonstrates the relationship GDP growth has on the rating. This variable seems to have its greatest impact over a much smaller range than per capita GDP. Furthermore, the relationship is clearly non-linear. Increases in the growth rate are beneficial in pushing the sovereign further into the investment grade ratings. However, beyond a certain point this effect is lost almost entirely.

Figure 2. Marginal Effects of per capita GDP and Growth on Ratings
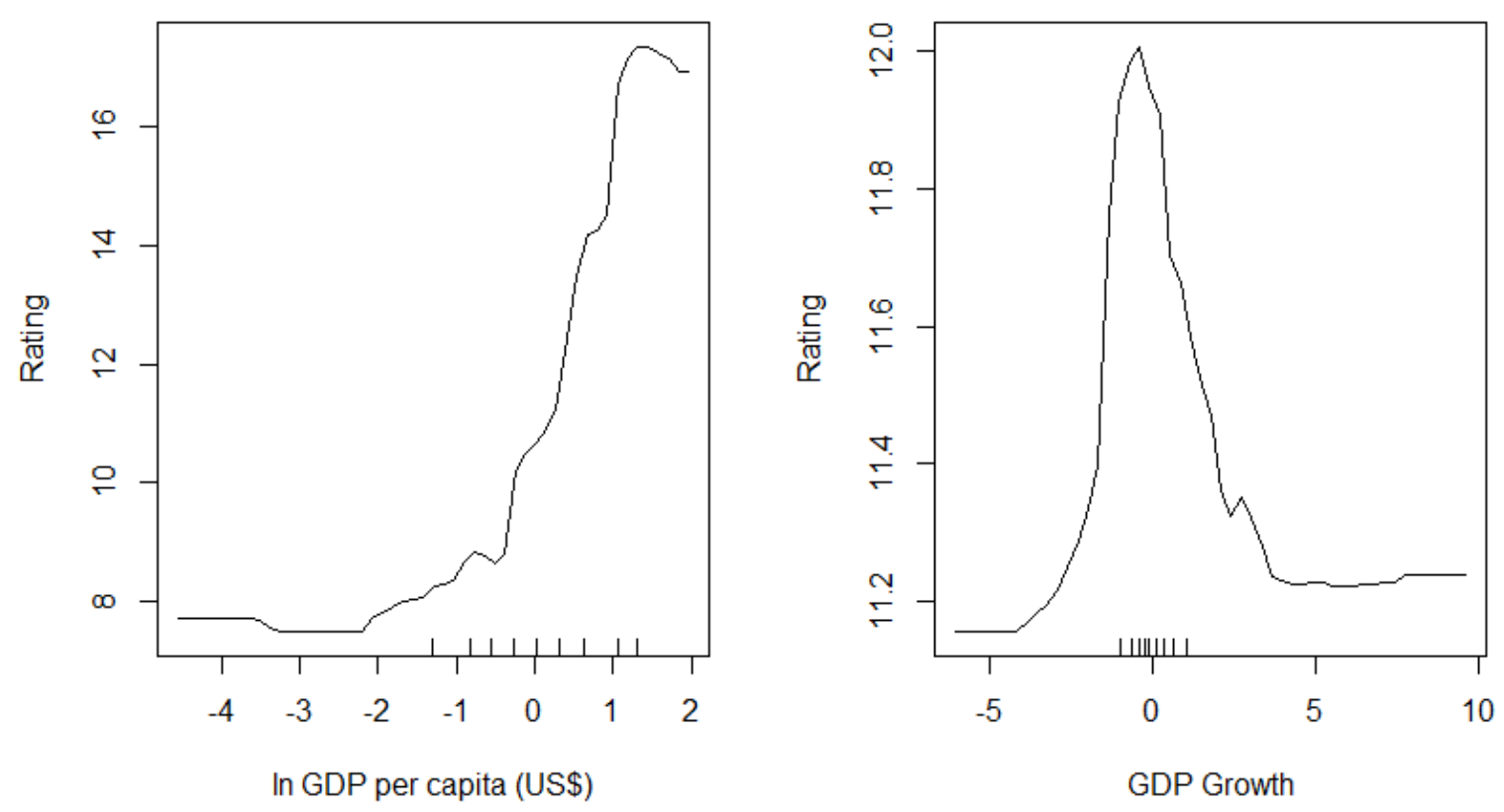
An important consideration is whether the variables considered important by our random forest procedure are consistent with those identified in the empirical literature on estimating sovereign ratings (Cantor and Packer 1996; Afonso et al., 2009; 2011; Baghai et al., 2016). Table 2 confirms this is the case, reporting variable importance in the random forest analysis across various subsamples. This analysis iterates through the list of predictor variables, imputing the values with random figures, and reassessing the estimation accuracy. The loss in accuracy (formally, increase in the mean square error) during this procedure is gauges the importance of each variable for predicting ratings. Table 2 provides estimates of the percentage increase in mean square error associated with the loss of variables commonly used to predict ratings.

Table 2. Variable importance (\% increase in MSE)

\begin{tabular}{lllll}
\hline & G20 subsample & Rest of the world & $\begin{array}{c}\text { Investment } \\
\text { grade }\end{array}$ & $\begin{array}{c}\text { Speculative } \\
\text { grade }\end{array}$ \\
& & & & 17.16 \\
\hline GDP per capita (US\$) & 12.20 & 29.32 & 40.47 & 7.15 \\
Real investment growth & 2.93 & 14.15 & 16.81 & 14.04 \\
Investment/GDP & 12.85 & 32.76 & 28.31 & 16.82 \\
Unemployment & 18.41 & 28.15 & 32.32 & 18.58 \\
CPI growth & 15.27 & 17.63 & 15.97 & 6.88 \\
Real exports growth & 0.08 & 6.55 & 6.39 & 17.52 \\
Current account & 8.79 & 27.88 & 17.69 & 8.54 \\
balance/GDP & & & & 18.59 \\
General government & 8.57 & 28.41 & 23.78 & 14.02 \\
balance/GDP & & & & 14.72 \\
Voice and accountability & 17.86 & 23.99 & 18.05 & \\
Political stability & 13.39 & 15.49 & 22.96 & 19.13 \\
Government & 13.75 & 25.69 & 27.68 & 18.13 \\
effectiveness & & & & 31.26 \\
Regulatory quality & 16.45 & 30.05 & 23.31 & \\
Control of corruption & 15.69 & 13.92 & & \\
\hline
\end{tabular}

Notes: Table presents the percentage increase in mean squared error attributable to the random forest prediction when the corresponding variable is imputed with random values. Column 2 presents the results for the G20 subsample, Column 3 corresponds to the rest of the world subsample, Column 4 contains investment grade only, and Column 5 relates to speculative grade only. Data sample covers period between 2004 and 2020. 
Key economic indicators demonstrate substantial value in this analysis, justifying their inclusion. However, notably a selection of World Bank governance indicators also provides reasonable explanatory power. This is especially true for countries outside of the G20 where e.g. political stability may be a greater constraint on ratings. Furthermore, columns 4 and 5 show the variation between countries with investment grade and speculative grade ratings. Amongst investment grade countries GDP per capita and associated economic indicators are the clear empirical driver of the rating. However, amongst speculative grade this is less clear. World Bank governance metrics play a much more important role alongside primary economic variables. This finding perhaps explains aspects of the see-saw effect observed in the main result. Countries at the lower end of the scale rely, to a greater extent, on qualitative, factors for a reliable rating prediction.

\section{Empirical results}

\subsection{Step 1: Reconstructing ratings}

Table 3 demonstrates our model's ability to predict sovereign existing sovereign ratings (i.e., before we incorporate climate change). Rows 2-5 indicate the deviation (in notches) between ratings issued by $\mathrm{S} \& \mathrm{P}$ and our predictions, starting with $\mathrm{N}=0$ (exact match) to $\mathrm{N}=3$ (our model is off by three notches). Columns 3-5 indicate increasingly restrictive slices of the data, starting with the whole sample in column 3, and providing results for out of sample tests (using $80 \%$ of the data to predict the remaining $20 \%$ ) for all countries in column 4 , and for only those countries with investment grade ratings in column 5.

Table 3. Predictive accuracy of our ratings prediction model

\begin{tabular}{lllll}
\hline & & Whole sample & $\begin{array}{c}\text { Out of sample } \\
\mathbf{8 0 / 2 0 \%} \text { split }\end{array}$ & $\begin{array}{c}\text { Investment grade } \\
\text { only. Out of sample } \\
\mathbf{8 0 / 2 0 \%}\end{array}$ \\
\hline \% predicted & $\mathrm{N}=0$ & 67.92 & 31.75 & 34.78 \\
within n notches & $\mathrm{N}=1$ & 96.24 & 76.19 & 63.77 \\
& $\mathrm{~N}=2$ & 99.69 & 90.48 & 81.16 \\
& $\mathrm{~N}=3$ & - & 94.44 & 92.75 \\
\hline Observations & & 639 & $513 / 126$ & $276 / 69$ \\
Countries & & 108 & 108 & $62 / 42$ \\
\hline
\end{tabular}

Notes: Table presents the results of the predictive capacity for our benchmark random forest model. Columns 35 show the percentage accuracy of our model corresponding to the number of notches in Column 2. Columns 3 , 
4 and 5 present the results for the whole sample, out of sample and investment grade only respectively. Data sample covers S\&P ratings issued 2015-2020.

Our benchmark model (column 4) yields exact matches between predicted and observed ratings $31.75 \%$ of the time, increasing to over $90 \%$ accuracy within two notches. The literature indicates that eliminating countries that have recently defaulted can improve predictive accuracy. To test this, column 5 restricts the analysis to only those countries with investment grade ratings. Although we see a minor increase in exact matches, we see a loss of accuracy within two notches in out of sample tests. One potential reason is that focusing only on investment grade sovereigns reduces the sample for training the model by nearly half. A further concern is that vulnerability to climate change may be correlated with low sovereign ratings, for instance if developing countries rely more heavily on climate-sensitive industries such as agriculture, have less climate resilient infrastructure (e.g., poor road quality or flood defences), and have lower quality governance and institutions associated with the resource curse. Eliminating these countries from the sample would make our results less representative. As such, our baseline model includes all 108 countries in the sample and is trained on S\&P's ratings issued between 2015 and 2020.

Figure 3 presents graphical interpretations of the out of sample accuracy of sovereign rating predictions given in Table 3 (column 4). The solid line depicts accuracy of the estimated rating compared to the actual rating. Each observation is accompanied by the predicted rating (dot) and its error. Out of sample predictions yield exact matches for up to $31.75 \%$ of the data and are within 2 notches over $90 \%$ of the time. Standard errors are produced using the jackknife methodology summarised in Wager et al. (2014).

Figure 4 demonstrates the geographical spread of our predictions model. The key observation is that high predictive accuracy does not appear to be concentrated in any particular region, climate, size, development status, or political system. Exact matches appear for countries as diverse as Brazil, Finland, Uganda, Germany, Honduras, and Mongolia. Most of the G20 countries are predicted within one notch. Argentina, Colombia, Ecuador and Iraq are the least well predicted by our model, which may be expected due to the history of debt crises, defaults, civil unrest, war, and government instability in these countries. This explanation is consistent with Table 2, column 5, which indicates the higher predictive weight placed on governance quality, corruption, and political stability for speculative grade countries. Because we do not 
have credible quantitative data on the effect of climate change on these governance indicators, they are not included in our ratings prediction model.

Figure 3. Out of sample accuracy of our ratings prediction model (2015 - 2020 data, all countries)

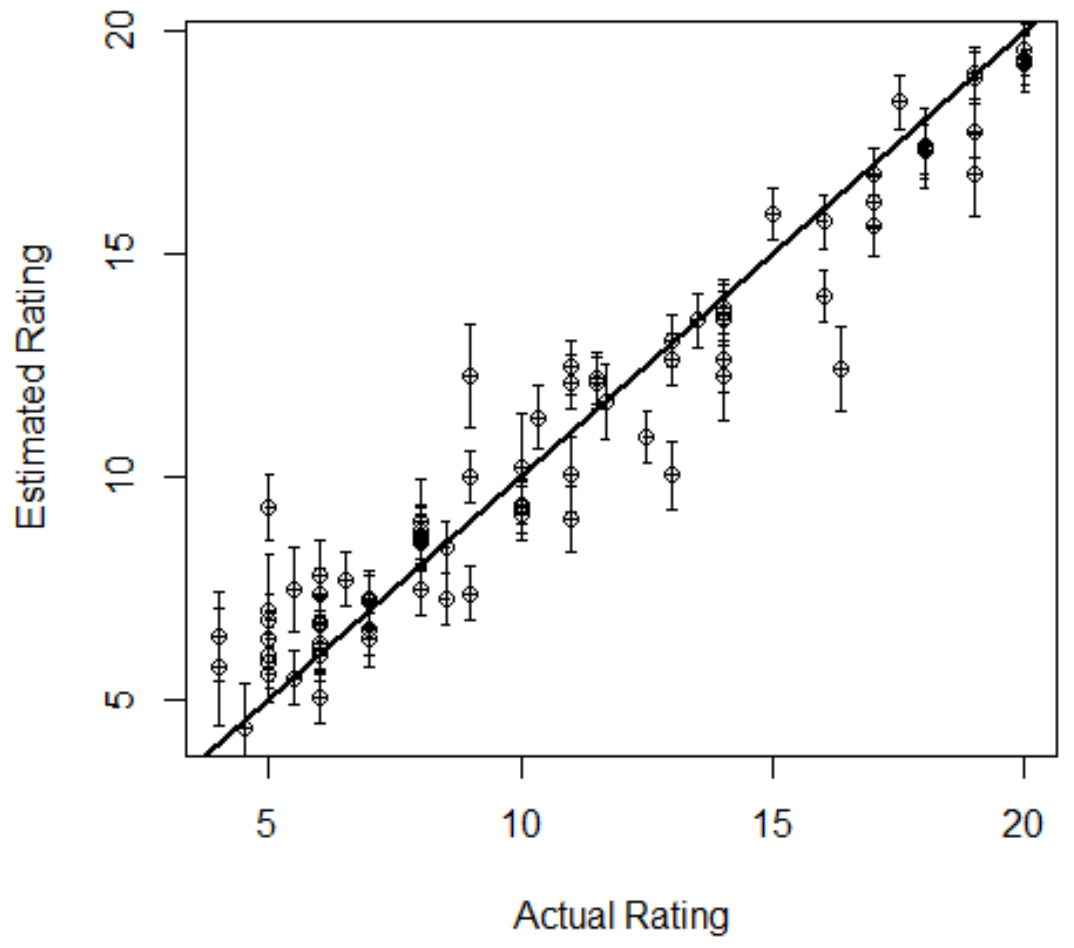

Figure 4. Out of sample predictive accuracy of our sovereign ratings model

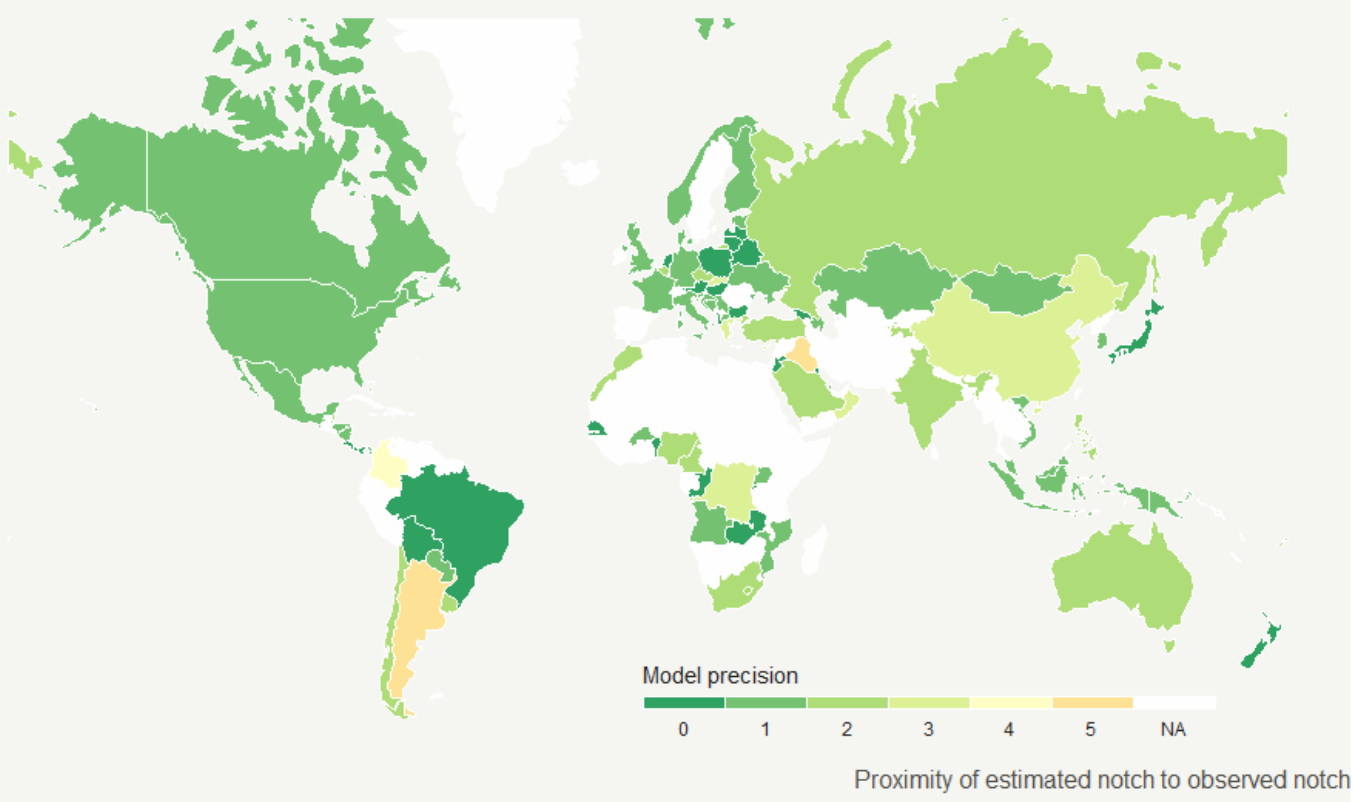




\subsection{Step 2: Climate adjusted sovereign ratings: baseline model}

We next present the results from our baseline mode ${ }^{10}$ under two warming scenarios (RCP 2.6 and RCP 8.5) for the years 2030, 2050, 2070, and 2100. ${ }^{11}$ All results presented here rely on the same macroeconometric climate model from Kahn et al. (2019). Panels A and B of Figure 5 present simulated, climate-adjusted sovereign ratings under RCP 8.5 and RCP 2.6 for the year 2030 respectively. As in Figure 3, the horizontal axis indicates current ratings by S\&P and the thick black line represents exact matches between current and predicted ratings. Here, however, our predicted ratings are inclusive of climate change under RCP 8.5, with the dotted line indicating best fit. The results indicate that climate-induced sovereign downgrades may be expected within the next decade and are most likely to impact the highest rated countries.

Figure 5. Climate-adjusted Ratings: 2030 (RCP 8.5 versus RCP 2.6)
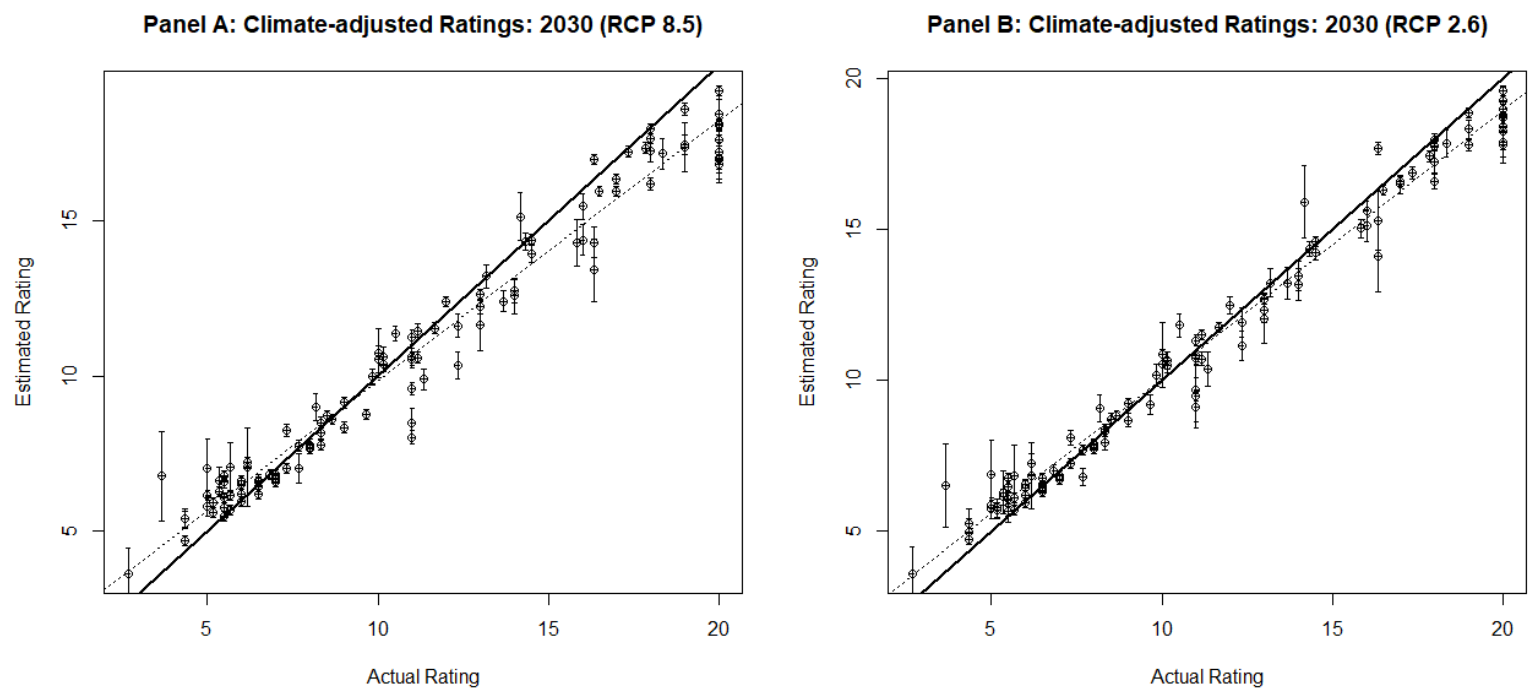

The concentration of downgrades at the top end of the ratings scale may appear counterintuitive, given that wealthier countries tend to have more diversified economies with greater capacity to respond to shocks. It may be expected that poorer countries (and therefore lower-rated sovereigns) are relatively more exposed and less able to respond to climate shocks. However, the underlying climate-economic model (Kahn et al., 2019) anticipates economic losses for countries at all development levels. For interpreting our results, it is important to remember that not all notches are created equal: a downgrade from AAA to AA+ reflects

\footnotetext{
${ }^{10} 108$ countries, using ratings from 2015 to 2020, 6-variables, Kahn et al. (2019) for the climate-economy model.

${ }^{11}$ Figures for 2050, 2070, 2100 are available upon request.
} 
smaller reduction in creditworthiness than a downgrade from investment grade to speculative grade, or a rating downgrade within the range of speculative ratings. This nonlinear relationship between rating and default frequency is demonstrated by the agencies' annual rating default and transition studies. Moreover, our objective is to identify the effect of climate change on sovereign ratings, not national economies. The fact that AAA rated countries may suffer worse downgrades than B rated ones does not imply that these wealthy countries will also suffer worse economic damages from climate change. Our result is consistent with the nature of sovereign ratings, which provide information about both the ability and willingness of sovereigns to service their debt. Countries with low ratings often already face a range of political, economic, and social challenges that indicate a low ability or willingness (or both) to service debt. Whilst we expect climate to have severe consequences for low-income countries, this may not further affect the rating if the country is already considered a high credit risk.

Finding downgrades just 10 years into the future is significant, as a common critique of the use of climate science in developing climate-finance metrics is that the timescales are incompatible: climate impacts accrue in the distant future, whereas financial decisions take place over a much shorter period. This conflict has been dubbed the "Tragedy of the Horizon" (Carney 2015). Our findings indicate that climate could impact ratings within the standard 10year ratings horizon.

Figure 5, Panel B presents results for the same simulation under RCP 2.6. Although some downgrades are still predicted at the top end of the scale, these are fewer in number and intensity than under RCP 8.5. This demonstrates the potential for stringent climate policy to reduce the downward effect of climate change on sovereign ratings within the next decade.

Figure 6 presents the best fit lines for our climate-adjusted ratings under RCP 8.5 and 2.6, respectively, for 2030, 2050, 2070, and 2100 (Panels A and B). Axes and the bold lines are interpreted in the usual way. Data points indicate current observed and predicted ratings, excluding climate change. Fig. 6, Panel A demonstrates climate-induced sovereign downgrades of increasing magnitude and across more countries as we look further into the future under RCP 8.5. Again, downgrades are largest at the top end of the ratings scale, but we begin to see impacts across the full range of investment grade sovereigns. In contrast, Panel B indicates that stringent climate policies consistent with RCP 2.6 continue to protect against substantial 
climate downgrades over the assessment period. ${ }^{12}$ T-tests indicate that ratings predicted over any period to 2100 under RCP 2.6 are not statistically significantly different from each other or from current ratings predicted without climate change.

Figure 6. Climate-adjusted ratings to 2100 (RCP 8.5 versus 2.6)
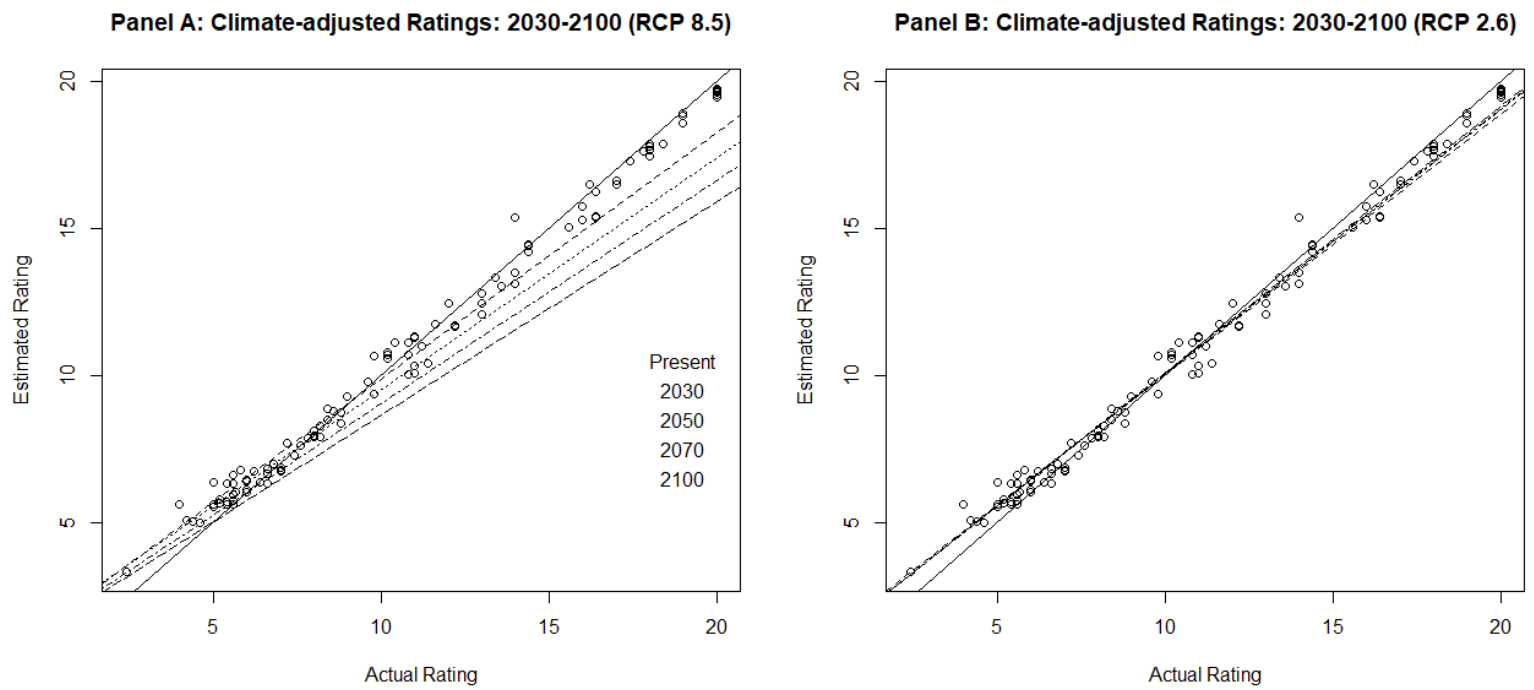

Figures 7-8 depict the magnitude and geographical distribution of sovereign ratings changes predicted by our model by 2100 under RCP 2.6 and RCP 8.5, respectively. Under RCP 2.6, 62 sovereigns experience downward pressure on ratings by 2030, with an average reduction of 0.66 notches. The number of downgraded sovereigns drops to 55 by 2100 , with the intensity of the downgrade virtually unchanged (average of 0.65 notches). Countries mostly affected by the downgrades are Chile and China with 2.56 and 2.05 notches respectively. Amongst other sovereigns we see Morocco, India and Colombia in the range 1.39 to 1.52 notches. This suggests that limiting warming to well below $2^{\circ} \mathrm{C}$ could greatly reduce the effect of climate change on sovereign ratings.

In contrast, under RCP 8.5, 63 sovereigns experience climate-induced downgrades by 2030, with an average reduction of 1.02 notches, rising to 80 sovereigns facing an average downgrade of 2.48 notches by 2100 . The most affected nations include Chile, China, Slovakia, Malaysia,

\footnotetext{
12 The tight bunching of best fit lines for 2030, 2050, 2070, and 2100 under RCP 2.6 around the bold line makes the time series difficult to discern graphically. T-tests confirm that they are not statistically significantly different from each other.
} 
Mexico, India, Peru and Canada all exceeding 5 notches downgrades. The least affected by downgrades are Oman, Cyprus and Honduras with results under 0.3 notches.

Figure 7. Global climate-induced sovereign ratings changes (2100, RCP 2.6)

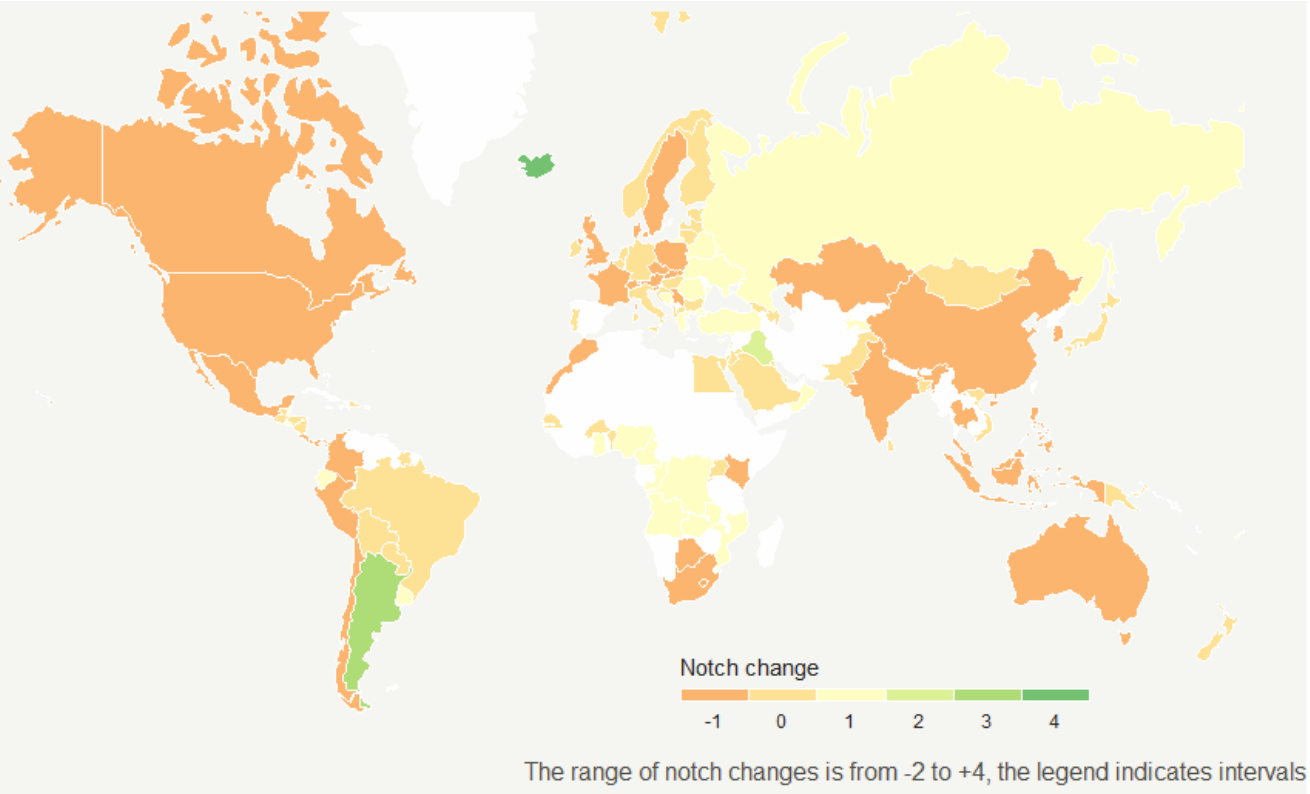

Figure 8. Global climate-induced sovereign ratings changes (2100, RCP 8.5)

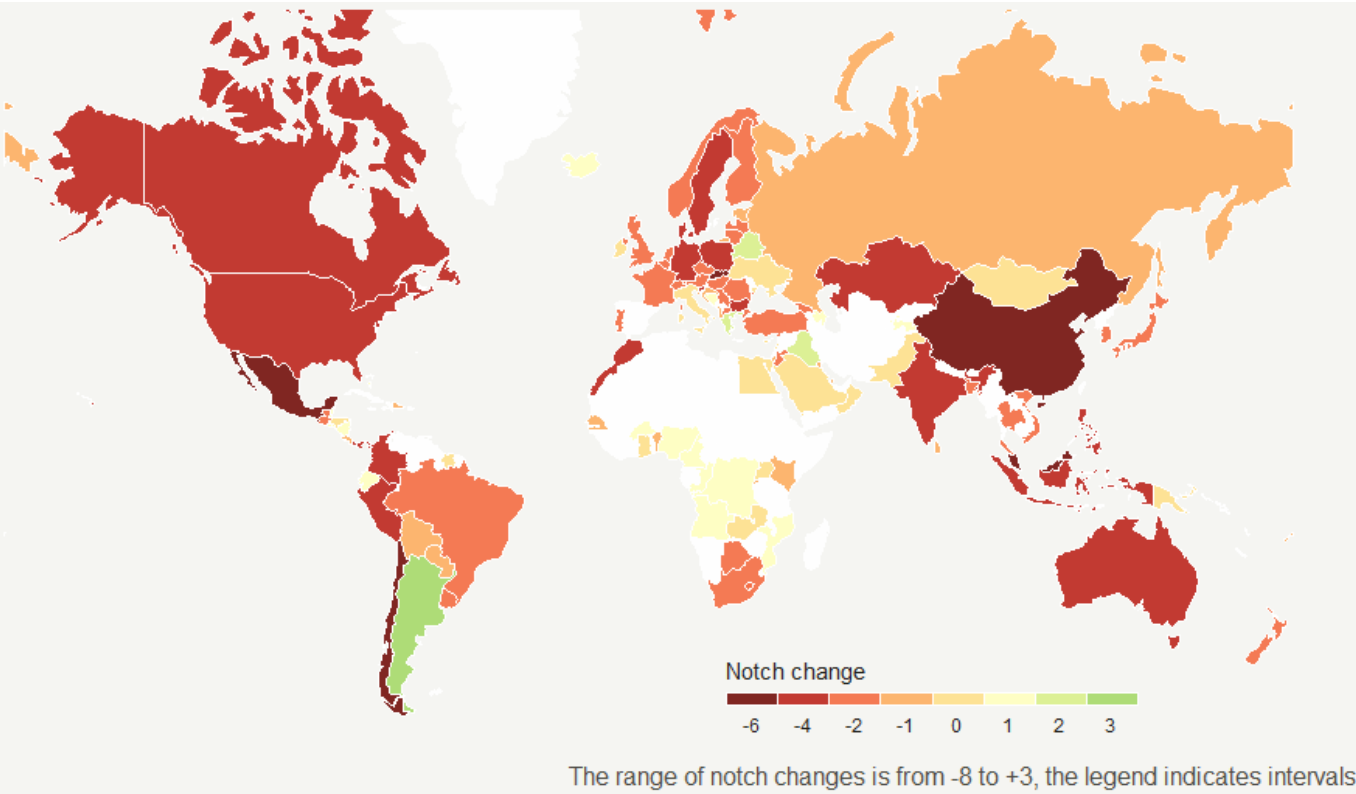

Combined, the maps indicate a now familiar story: stringent climate policy under RCP 2.6 and largely consistent with the Paris Climate Agreement is associated with only minor downgrades 
across most of the world. In both figures, some countries (Argentina, Iraq, and Ecuador) appear to receive upgrades. We urge extreme caution against over-interpreting these counterintuitive findings, as our model's predictive capacity for these countries is relatively low (see Figure 4). This is likely because factors not included in our model such as political stability and default history in these countries mean that current ratings are relatively low for their GDP (see Table 2 and surrounding text). Our model does not include governance and political stability metrics because we do not have authoritative quantitative data on how these measures are likely to change as a result of climate change.

\subsection{Increased temperature variability}

Our baseline model relies on Kahn et al. (2019) to describe the impacts of warming on real GDP and GDP growth rates. They explicitly model changes in the distribution of weather patterns; that is not only averages of climate variables that the climate-macro literature focuses on but also their variability. Therefore, this model enables us to incorporate varying degrees of temperature volatility within the overall warming trend. Put simply, we can choose whether warming is characterized by high and low temperatures that cluster tightly around their 30-year moving averages, or whether they deviate with increasing volatility as temperature rises. Lower volatility could reduce shocks and means adaptation costs can be spread over time. Higher volatility may require more upfront investments and lead to asset stranding. Beyond rises in the average, rises in the volatility of temperature are increasingly recognised as economically important. For instance, Kotz et al. (2021) find that increased temperature volatility reduces economic growth "independent of and in addition to changes in annual average temperature."

To incorporate the effects of increased temperature volatility in our model, we allow temperature increases to affect the variability of temperature shocks commensurately, or in other words we keep the coefficient of variation unchanged. On average, this increases the costs of climate change by $80 \%$ globally under the RCP 8.5 scenario, with the size of these income effects varying across countries depending on the pace with which temperatures increase and historical variability of climate conditions in each country.

Compared to Panel B of Figure 6, Panel B of Figure 9 indicates that climate change will have a larger impact on sovereign ratings if temperature volatility rises, even under RCP 2.6. 
However, although the effect is marginally larger, it remains the case that stringent policies consistent with RCP 2.6 will limit the effect of climate on sovereign ratings. In contrast, Fig 9, Panel A demonstrates that increased temperature volatility leads to far more substantial climate-induced sovereign downgrades, sooner, and along a much wider range of the ratings scale.

Figure 9. Climate-adjusted ratings with increased temperature volatility (RCP 8.5 versus 2.6)
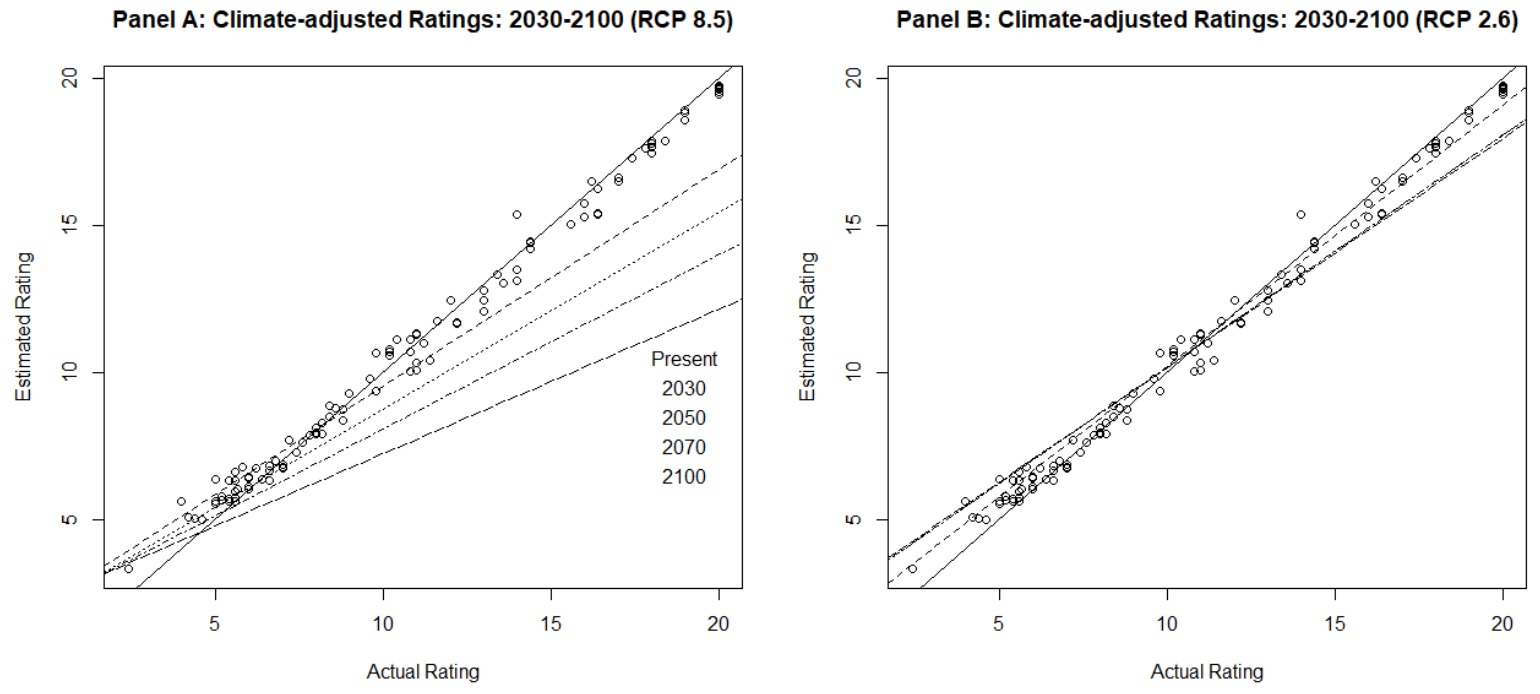

\section{Additional cost of sovereign and corporate borrowing due to climate-induced sovereign downgrades}

Previous research demonstrates that sovereign downgrades increase sovereign spreads (Afonso et al., 2012; Gande and Parsley 2005). Estimates of the effect of a 1-notch downgrade in sovereign rating on increases in yield spreads range from $0.08-0.112 \%$ (Afonso et al., 2012) to 0.12\% (Gande and Parsley 2005). Taking these as lower and upper bounds (respectively) enables us to calculate ranges for the increase in annual interest payments on public debt due to climate-induced sovereign downgrades. Table 4 reports these costs for the G7 plus China under RCP 2.6 scenario by 2100 . Columns 2-3 present climate-induced sovereign downgrades (in notches) and total outstanding sovereign debt as of 2019. Columns 4-5 report lower and upper bound estimates of the additional cost of sovereign debt due to climate downgrades. Climate-induced sovereign downgrades could increase the cost of sovereign debt across our sample by US\$ 22.47 billion to US\$ 34.11 billion under RCP 2.6. These costs are more than 6 times larger under RCP 8.5, with a lower-bound of US\$ 136.68 billion and an upper-bound of US\$205.02 billion (see Table 5). 
Table 4. Additional cost of sovereign borrowing due to climate-induced sovereign downgrades (RCP 2.6, 2100)

\begin{tabular}{|c|c|c|c|c|}
\hline Sovereign & $\begin{array}{c}\text { Sovereign } \\
\text { downgrade } \\
\text { (notches) }\end{array}$ & $\begin{array}{c}\text { Outstanding } \\
\text { sovereign debt } \\
(\$ \text { bn })\end{array}$ & $\begin{array}{c}\text { Cost of } \\
\text { sovereign } \\
\text { borrowing (\$ } \\
\text { bn) (lower } \\
\text { bound) }\end{array}$ & $\begin{array}{c}\text { Cost of } \\
\text { sovereign } \\
\text { borrowing (\$ } \\
\text { bn) (upper } \\
\text { bound) }\end{array}$ \\
\hline Canada & 0.58 & 557.10 & 0.26 & 0.39 \\
\hline China & 2.05 & 2464.40 & 4.04 & 6.06 \\
\hline France & 0.83 & 2026.10 & 1.35 & 2.02 \\
\hline Germany & 0.23 & 1254.30 & 0.23 & 0.35 \\
\hline Japan & 0.36 & 10396.20 & 2.99 & 4.49 \\
\hline United Kingdom & 0.92 & 2710.70 & 2.00 & 2.99 \\
\hline United States & 0.55 & 16673.40 & 7.34 & 11.00 \\
\hline G7 + China & 0.79 & 36082.20 & 18.18 & 27.27 \\
\hline Full sample total & 0.65 & 42716.80 & 22.74 & 34.11 \\
\hline
\end{tabular}

Notes: Translating climate-induced sovereign downgrades into increased sovereign cost of borrowing by 2100 under RCP 2.6 scenario for G7 plus China. Italy is not downgraded under this scenario. Full sample results for 55 downgraded sovereigns available in Appendix D, Table D.1. Outstanding sovereign debt figures for 2019 obtained from S\&P SRIs. Conversion between sovereign downgrades into yields for lower bound is based on Afonso et al. (2012) and for upper bound on Gande \& Parsley (2005), whereby 1 notch sovereign downgrade increases sovereign bond spread by $0.08 \%$ and $0.12 \%$ respectively.

Table 5. Additional cost of sovereign borrowing due to climate-induced sovereign downgrades (RCP 8.5, 2100)

\begin{tabular}{|c|c|c|c|c|}
\hline Sovereign & $\begin{array}{c}\text { Sovereign } \\
\text { downgrade } \\
\text { (notches) }\end{array}$ & $\begin{array}{c}\text { Outstanding } \\
\text { sovereign debt } \\
\text { (\$ bn) }\end{array}$ & $\begin{array}{c}\text { Cost of } \\
\text { sovereign } \\
\text { borrowing (\$ } \\
\text { bn) (lower } \\
\text { bound) } \\
\end{array}$ & $\begin{array}{c}\text { Cost of } \\
\text { sovereign } \\
\text { borrowing (\$ } \\
\text { bn) (upper } \\
\text { bound) } \\
\end{array}$ \\
\hline Canada & 5.15 & 557.10 & 2.30 & 3.44 \\
\hline China & 6.55 & 2464.40 & 12.91 & 19.37 \\
\hline France & 2.43 & 2026.10 & 3.94 & 5.91 \\
\hline Germany & 3.65 & 1254.30 & 3.66 & 5.49 \\
\hline Italy & 0.30 & 2225.30 & 0.53 & 0.80 \\
\hline Japan & 2.39 & 10396.20 & 19.88 & 29.82 \\
\hline United Kingdom & 3.48 & 2710.70 & 7.55 & 11.32 \\
\hline United States & 4.74 & 16673.40 & 63.23 & 94.84 \\
\hline G7 + China & 3.59 & 38307.50 & 113.93 & 170.89 \\
\hline Full sample total & 2.48 & 47326.70 & 136.68 & 205.02 \\
\hline
\end{tabular}

Notes: Translating climate-induced sovereign downgrades into increased sovereign cost of borrowing by 2100 under RCP 8.5 scenario for G7 plus China. Full sample results for 80 downgraded sovereigns available in Appendix D, Table D.2. Outstanding sovereign debt figures for 2019 obtained from S\&P SRIs. Conversion 
between sovereign downgrades into yields for lower bound is based on Afonso et al. (2012) and for upper bound on Gande \& Parsley (2005), whereby 1 notch sovereign downgrade increases sovereign bond spread by $0.08 \%$ and $0.12 \%$ respectively.

Translating sovereign rating changes into impacts on corporate cost of capital is more challenging, as no such direct translation exists in the literature. However, Almeida et al (2017) quantify a sovereign spillover effect from sovereign to corporate ratings, whereby a one percentage point increase in sovereign yields increases corporate yields by a factor of 0.6-0.7. We follow three-step procedure to calculate the effect of climate-induced sovereign ratings on the cost of corporate capital (see Tables 6 and 7 for RCP 2.6 and 8.5 respectively). ${ }^{13}$ First, we translate sovereign downgrades into sovereign yield spreads as described above and reported in Tables $4-5$. Second, we multiply these values $(0.08 \%$ versus $0.12 \%)$ by the magnitude of the spillover effect from sovereign to corporate yields identified in Almeida et al (2017), treating $0.6(0.7)$ as the lower (upper) bound. ${ }^{14}$ Finally, we calculate the resulting costs of outstanding corporate debt in all countries in which we have data. Using data from the Bank of International Settlements (BIS), Table 6, column 3 reports outstanding corporate debt in US\$ billion for the G7 + China as of June 2020. The availability of BIS data on corporate debt restricts our calculations to a sub-sample of 28 (34) countries under RCP 2.6 (8.5).

Lower- and upper-bound estimates of increases in the cost of corporate debt due to climateinduced sovereign downgrades are reported in columns 4-5. Under RCP 2.6, the lower (upper) bound estimates of the additional annual interest payments due to spillover of sovereign downgrades onto corporations will reach US\$ 7.21 (12.62) billion by 2100 across all 28 sovereigns for which BIS data is available. It is worth noting that this is the indirect effect of increased sovereign credit risk induced by climate change and passed onto corporates. These costs can be considered in addition to the direct effects of climate change on corporates (e.g. physical, transition, and litigation losses). The magnitude of the sovereign downgrades increases corporate interest outlays significantly (almost 5 times) under the RCP 8.5 scenario and exceeds 35.76 (62.59) \$ billion for lower (upper) bound, respectively.

\footnotetext{
13 As before in these tables we report G7 countries plus China but results for the full sample are available in Appendix D, Tables D.1.-D.4.

${ }_{14}$ Authors estimate the effect around the investment versus speculative grade threshold. These results are for illustrative purposes only and should be considered with caution. We realise taking this measure and applying it to all corporate debt held by a sovereign is conservative since not all firms will be rated around that threshold.
} 
Table 6. Additional cost of corporate debt due to climate-induced sovereign downgrades (RCP 2.6, 2100)

\begin{tabular}{lcccc}
\hline Sovereign & $\begin{array}{c}\text { Sovereign } \\
\text { downgrade } \\
\text { (notches) }\end{array}$ & $\begin{array}{c}\text { Outstanding } \\
\text { corporate debt } \\
(\mathbf{\$} \text { bn) }\end{array}$ & $\begin{array}{c}\text { Increase in cost } \\
\text { of debt } \mathbf{( \$ \mathbf { b n } )} \\
\text { lower bound }\end{array}$ & $\begin{array}{c}\text { Increase in cost } \\
\text { of debt } \mathbf{( \$ \mathbf { b n } )} \\
\text { upper bound }\end{array}$ \\
\hline Canada & 0.58 & 515 & 0.14 & 0.25 \\
China & 2.05 & 4061 & 4.00 & 6.99 \\
France & 0.83 & 777 & 0.31 & 0.54 \\
Germany & 0.23 & 241 & 0.03 & 0.05 \\
Japan & 0.36 & 845 & 0.15 & 0.26 \\
United Kingdom & 0.92 & 564 & 0.25 & 0.44 \\
United States & 0.55 & 7126 & 1.88 & 3.29 \\
\hline G7 + China & 0.79 & 14129 & 5.35 & 9.36 \\
Total BIS & $\mathbf{0 . 7 3}$ & $\mathbf{1 5 3 5 6}$ & $\mathbf{7 . 2 1}$ & $\mathbf{1 2 . 6 2}$ \\
\hline
\end{tabular}

Notes: Translating climate-induced sovereign downgrades into increased corporate cost of debt by 2100 under RCP 2.6 scenario. G7 plus China results presented here. Italy is not presented as it is not downgraded under this scenario. Data availability from BIS on corporate debt restricts our sample to 28 countries. Sub-sample results for the remaining 21 sovereigns calculated using BIS database available in Appendix D, Table D.3. To calculate the value of corporate debt affected by sovereign downgrades we first convert the sovereign rating changes into sovereign yield which we then convert into corporate sovereign yield. To translate sovereign ratings into yields we use lower bond $(0.08 \%)$ from Afonso et al. (2012) and higher bound (0.12\%) from Gande \& Parsley (2005). To then convert these into corporate spreads we use Almeida et al. (2017)' conversions, with 0.6 for lower bound and 0.7 for higher bound. We multiply sovereign rating changes (see column 2) by an amount of outstanding debt at end-June 2020 (column 3) and 0.00048 for a lower bound $(0.08 \% * 0.6)$ and $0.00084(0.12 \% * 0.7)$ for a upper bound respectively.

Table 7. Additional cost of corporate debt due to climate-induced sovereign downgrades (RCP 8.5, 2100)

\begin{tabular}{|c|c|c|c|c|}
\hline Sovereign & $\begin{array}{c}\begin{array}{c}\text { Sovereign } \\
\text { downgrade } \\
\text { (notches) }\end{array} \\
\end{array}$ & $\begin{array}{c}\text { Outstanding } \\
\text { corporate debt } \\
(\$ \text { bn })\end{array}$ & $\begin{array}{l}\text { Increase in cost } \\
\text { of debt }(\$ \text { bn) } \\
\text { lower bound }\end{array}$ & $\begin{array}{l}\text { Increase in cost } \\
\text { of debt ( } \$ \text { bn) } \\
\text { higher bound }\end{array}$ \\
\hline Canada & 5.15 & 515 & 1.27 & 2.23 \\
\hline China & 6.55 & 4061 & 12.77 & 22.34 \\
\hline France & 2.43 & 777 & 0.91 & 1.59 \\
\hline Germany & 3.65 & 241 & 0.42 & 0.74 \\
\hline Italy & 0.3 & 152 & 0.02 & 0.04 \\
\hline Japan & 2.39 & 845 & 0.97 & 1.70 \\
\hline United Kingdom & 3.48 & 564 & 0.94 & 1.65 \\
\hline United States & 4.74 & 7126 & 16.21 & 28.37 \\
\hline G7 + China & 3.16 & 10220 & 20.75 & 36.31 \\
\hline Total BIS & 3.28 & 15561 & 35.76 & 62.59 \\
\hline
\end{tabular}

Notes: Translating climate-induced sovereign downgrades into increased corporate cost of debt by 2100 under RCP 8.5 scenario. G7 plus China results presented here. Data availability from BIS on corporate debt restricts our sample to 34 countries. Sub-sample results for the remaining 26 sovereigns calculated using BIS database available in Appendix D, Table D.4. To calculate the value of corporate debt affected by sovereign downgrades we first convert the sovereign rating changes into sovereign yield which we then convert into corporate sovereign yield. To translate sovereign ratings into yields we use lower bond (0.08\%) from Afonso et al. (2012) and higher bound $(0.12 \%)$ from Gande \& Parsley (2005). To then convert these into corporate spreads we use Almeida et al. (2017)' conversions, with 0.6 for lower bound and 0.7 for higher bound. We multiply sovereign rating changes (see column 2) by an amount of outstanding debt at end-June 2020 (column 3) and 0.00048 for a lower bound $(0.08 \% * 0.6)$ and $0.00084(0.12 \% * 0.7)$ for a higher bound respectively. 
The above calculations show that impacts of climate-induced sovereign downgrades on debt servicing costs are large in magnitude for both sovereigns and corporates. With maturities of debt products extending ${ }^{15}$ and meaningful economic implications of climate change drawing nearer, investors will progressively need more reliable credit opinions beyond the relatively short-term 5-10 years horizon ${ }^{16}$ offered by CRAs today. This research has set the foundations for such a longer-term view. Based on the methodology applied here, future research could focus on the development of ultra-long ratings that investors could consider when assessing long-dated sovereign credit exposures. Currently CRAs apply the same "long-term" rating to a 2-year bond as they do to a 50-year or century-bond. This equalisation of risk is clearly implausible. A transparent and scientifically grounded truly long-term rating will help support better investment decisions today, expose stranded assets earlier and create incentives for public policies and investments that contribute to containing and mitigating climate change. Such an instrument would therefore promote the global public good of climate protection and diminish the market failure that has created the climate crisis in the first place. Truly long-term credit views can help make climate risks visible within mainstream financial indicators, thus supporting investors to take decisions that are environmentally and financially sustainable for the long haul. ${ }^{17,18}$

Our research has strong policy implications for CRAs' regulators including ESMA and SEC. Significant changes due to climate change and aging societies are inevitable and sovereign credit ratings are not designed to reflect those ultra-long-term risks. Additionally, the "up to ten-year" horizon that CRAs pursue is not credible. Credit reports on sovereigns will include forecasts that typically only reach three years into the future, at most, and exceptionally to five. Regulators could therefore insist that CRAs document how they fulfil their current claim of a 5 to 10 -year time horizon. In a second step regulators should require CRAs to demonstrate how

\footnotetext{
${ }^{15}$ For instance, governments issue ever-longer dated bonds as long as 100 years (e.g., Argentina, Austria, Belgium, Ireland).

${ }^{16}$ CRAs issue what they refer to as "long-term" ratings but the time horizon extends to no more than 5-10 years, which is a fraction of the length of some of the bonds now being sold, and a relatively short period compared to the process of climate change.

17 This will alleviate concerns raised by many in relation to climate service providers who "operate outside of the bounds of scientific merit" (Keenan 2019) and misuse climate models (Nissan et al., 2019).

${ }^{18}$ One important concern is whether predicting climate-induced downgrades in the future may increase the cost of debt today. This is particularly concerning for low-income countries where evidence suggests that climaterelated natural disasters are already hitting bond yields (Beirne et al., 2020; Buhr et al., 2018; Kling et al., 2018). If investors believed that e.g., India is not a climate-safe investment, the perverse result could be to starve India of the access to capital it needs to increase resilience.
} 
they intend to incorporate long-term challenges such as demographic or climate change. Regulators must begin to look at more fundamental credit issues that could over a longer period impact the functioning of the capital market and its stability.

\section{Concluding remarks}

This research contributes to bridging the gap between climate science and real-world financial indicators. Combining climate science with economics, machine learning, and practitioner expertise, we simulate the effect of climate change on sovereign creditworthiness, producing the world's first climate-adjusted sovereign credit rating. The analysis is conducted using two distinct climate-economy models and yields qualitatively similar results under various warming scenarios. We document three key empirical findings. In contrast to much of the climate-economics literature, we find material impacts of climate change as early as 2030, with significantly deeper downgrades across more sovereigns as climate warms and temperature volatility rises. Under RCP 8.5, the average sovereign downgrade could reach 2.48 notches, with several countries falling 5 notches or more on a 20 -notch scale. Second, our findings suggest that stringent climate policy consistent with the Paris Agreement will result in minimal changes to sovereign creditworthiness. Finally, from policy perspective, our results support the idea that deferring green investments will increase costs of borrowing for sovereigns, which in line with the existing literature will translate into higher costs of corporate debt. The additional costs to sovereigns in our sample range from US\$ 22 to 33 billion under RCP 2.6, and US\$ 137 to 205 billion under RCP 8.5. Corporates will experience additional costs of between US\$ 7.2 and 12.6 billion under RCP 2.6, and between US $\$ 35.8$ and 62.6 billion under RCP 8.5.

Perhaps most importantly, our approach demonstrates that it is possible to 'do ESG' without compromising scientific credibility. We show that existing climate science and economics are capable of supporting credible, decision-ready green finance indicators.

This research is of interest to investors, sovereigns and CRAs alike. Governments issue everlonger dated bonds, of which life insurance companies and pension funds are eager buyers, thus enabling them to match their own long-term liabilities. Therefore, investors should consider the long-term creditworthiness of sovereign issuers. Currently there is no reliable yardstick for assessing sovereign creditworthiness beyond the current decade and this research fills this gap. Our study offers a first methodological approach to extend the long-term rating to an ultra-long-term reality. Based on the methodology applied here future research could 
focus on developing ultra-long ratings not only for sovereigns but also for other issuers including corporates.

\section{References}

Acharya V, Drechsler I, Schnabl P (2014) A pyrrhic victory? Bank bailouts and sovereign credit risk. Journal of Finance. 69:2689-2739.

Adelino M, Ferreira MA (2016) Bank ratings and lending supply: Evidence from sovereign downgrades. Review of Financial Studies. 29:1709-1746.

Afonso A, Furceri D, Gomes P (2012) Sovereign credit ratings and financial markets linkages: Application to European data. Journal of International Money \& Finance. 31:606-638.

Afonso A, Gomes P, Rother P (2009) Ordered response models for sovereign debt ratings., Applied Economics Letters. 16:769-773.

Almeida H, Cunha I, Ferreira MA, Restrepo F (2017) The real effects of credit ratings: The sovereign ceiling channel. Journal of Finance. 72:249-290.

Arezki R, Candelon B, Sy A (2011) Sovereign rating news and financial markets spillovers: Evidence from the European debt crisis. International Monetary Fund (IMF), Working paper No. 11/68.

Auffhammer M (2018) Quantifying economic damages from climate change. Journal of Economic Perspectives. 32:33-52.

Augustin P, Boustanifar H, Breckenfelder J, Schnitzler J (2018) Sovereign to corporate risk spillovers. Journal of Money, Credit \& Banking. 50:857-891.

Baghai RP, Servae H, Tamayo A (2014) Have rating agencies become more conservative? Implications for capital structure and debt pricing. Journal of Finance. 69:1961-2005.

Bastien-Olvera BA, Moore FC (2020) Use and non-use value of nature and the social cost of carbon. Nature Sustainability. 4:101-108.

Baum CF, Schäfer D, Stephan A (2016) Credit rating agency downgrades and the Eurozone sovereign debt crises. Journal of Financial Stability. 24:117-131.

Beirne J, Renzhi N, Volz U (2020) Feeling the heat: Climate risks and the cost of sovereign borrowing. Working paper, ADBI 1160.

Bennell JA, Crabbe D, Thomas S, ap Gwilym O (2006) Modelling sovereign credit ratings: Neural networks versus ordered probit. Expert Systems with Applications. 30:415-425.

Berg F, K"olbel J, Rigobon R (2019) Aggregate confusion: The divergence of ESG ratings. MIT Sloan Research Paper No. 5822-19.

Borensztein E, Cowan K, Valenzuela P (2013) Sovereign ceiling lite? The impact of sovereign ratings on corporate ratings in emerging market economies. Journal of Banking \& Finance. 37:40144024.

Breiman L (2001) Random forests. Machine learning. 45:5-32.

Brooks R, Faff RW, Hillier D, Hillier J (2004) The national market impact of sovereign rating changes. Journal of Banking \& Finance. 28:233-250.

Buhr B, Volz U, Donovan C, Kling G, Murinde V, Pullin NLY (2018) Climate change and the cost of capital in developing countries. Assessing the impact of climate risks on sovereign borrowing costs. Imperial College Business School May 2018.

Burke M, Hsiang SM, Miguel E (2015) Global non-linear effect of temperature on economic production. Nature. 527:235-239.

Cantor R, Packer F (1996) Determinants and impact of sovereign credit ratings. Economic Policy Review. 2(2).

Capelle-Blancard G, Crifo P, Diaye M, Scholtens B, Oueghlissi R (2017) Environmental, social and governance (ESG) performance and sovereign bond spreads: An empirical analysis of OECD countries. Working paper, SSRN 2874262.

Carney M (2015) Breaking the Tragedy of the Horizon - climate change and financial stability. Bank of England . 
Chen SS, Chen HY, Chang CC, Yang SL (2016) The relation between sovereign credit rating revisions and economic growth. Journal of Banking \& Finance. 64:90-100.

Cevik S, Jalles JT (2020a) Feeling the heat: Climate shocks and credit ratings. Working paper, IMF $2020 / 286$.

Cevik S, Jalles JT (2020b) This changes everything: Climate shocks and sovereign bonds. Working paper, IMF 20/79.

Cevik S, Jalles JT (2020c) An apocalypse foretold: Climate shocks and sovereign defaults. Working paper, IMF 20/231.

Cornaggia JN, Cornaggia KJ, Hund JE (2017) Credit ratings across asset classes: A long-term perspective. Review of Finance. 21:465-509.

Crifo P, Diaye M, Oueghlissi R (2015) Measuring the effect of government ESG performance on sovereign borrowing cost. Working paper, Hal Departement D'economie Route de Saclay hal00951304.

Dell M, Jones BF, Olken BA (2014) What do we learn from the weather? The new climate- economy literature. Journal of Economic Literature. 52:740-798.

Dell M, Jones BF, Olken BA (2012) Temperature shocks and economic growth: Evidence from the last half century. American Economic Journal: Macroeconomics. 4:66-95.

Deutsche Bundesbank (2019) Climate change and central banks.

Diaz D Moore F (2017) Quantifying the economic risks of climate change. Nature Climate Change. 7:774-782.

Dietz S, Bowen A, Dixon C, Gradwell P (2016) "Climate value at risk" of global financial assets. Nature Climate Change. 6:676-679.

Dietz S, Stern N (2015) Endogenous growth, convexity of damage and climate risk: How Nordhaus' framework supports deep cuts in carbon emissions. Economic Journal. 125: 574-620.

De Moor L, Luitel P, Sercu P, Vanpée R (2018) Subjectivity in sovereign credit ratings. Journal of Banking \& Finance. 88:366-392.

Fiedler T, Pitman AJ, Mackenzie K, Wood N, Jakob C, Perkins-Kirkpatrick SE (2021). analytics. Business risk and the emergence of climate analytics. Perspective. Nature Climate Change.

Fioramanti M, (2008) Predicting sovereign debt crises using artificial neural networks: A comparative approach. Journal of Financial Stability. 4:149-164.

Gande A, Parsley DC (2005) News spillovers in the sovereign debt market. Journal of Financial Economics. 75:691-734.

Gennaioli N, Martin A, Rossi S (2014) Sovereign default, domestic banks, and financial institutions. Journal of Finance. 69:819-866.

Hausfather Z, Peters GP (2020) Emissions - the "business as usual" story is misleading. Nature. 577: 618-620.

Hepburn C, O'Callaghan B, Stern N, Stiglitz J, Zenghelis D (2020) Will COVID-19 fiscal recovery packages accelerate or retard progress on climate change? Oxford Review of Economic Policy.

Howard-Grenville J (2021) ESG impact is hard to measure - but it's not impossible. Harvard Business Review.

Kahn ME, Mohaddes K, Ng RNC, Pesaran MH, Raissi M, Yang J-C (2019) Long-term macroeconomic effects of climate change: A cross-country analysis. National Bureau of Economic Research Working Paper 26167.

Kaminsky G, Schmukler SL (2002) Emerging market instability: Do sovereign ratings affect country risk and stock returns? World Bank Economic Review. 16:171-195.

Keenan JM (2019) A climate intelligence arms race in financial markets. Science. 365:1240-1243.

Kling G, Lo YC, Murinde V, Volz U (2018) Climate vulnerability and the cost of debt. Working paper, SSRN 3198093.

Kotz M, Wenz L, Stechemesser A, Kalkuhl M, Levermann A (2021) Day-to-day temperature variability reduces economic growth. Nature Climate Change.

Markellos R, Psychoyios D, Schneider F (2016) Sovereign debt markets in light of the shadow economy. European Journal of Operational Research. 252:220-231.

Mathiesen K (2018) Rating climate risks to credit worthiness. Nature Climate Change. 8:454-456. 
Mellios C, Paget-Blanc E (2006) Which factors determine sovereign credit ratings? European Journal of Finance. 12:361-377.

Moss R, Edmonds J, Hibbard K, Manning M, Rose S, van Vuuren D, Carter T, Emori S, Kainuma M, Kram T, Meehl G, Mitchell J, Nakicenovic N, Riahi K, Smith S, Stouffer R, Thomson A, Weyant J, Wilbanks T (2010) The next generation of scenarios for climate change research and assessment. Nature. 463:747-756.

Mulder CB, Monfort B (2014) Using credit ratings for capital requirements on lending to emerging market economies: Possible impact of a new Basel Accord. Working paper, IMF 0069.

Nissan H, Goddard L, de Perez EC, Furlow J, Baethgen W, Thomson MC, Mason SJ (2019) On the use and misuse of climate change projections in international development. Wiley Interdisciplinary Reviews: Climate Change. 10(d579).

Nordhaus WD, Boyer J (2000) Warming the world: Economic models of global warming. Cambridge, MA: The MIT Press.

Opimas (2020) ESG data market: No stopping its rise now. White paper.

Ozturk H, Namli E, Erdal H (2016) Modelling sovereign credit ratings: The accuracy of models in a heterogeneous sample. Economic Modelling. 54:469-478.

Painter M (2020) An inconvenient cost: The effects of climate change on municipal bonds. Journal of Financial Economics. 135:468-482.

Pindyck RS, (2013) Climate change policy: What do the models tell us? Journal of Economic Literature. 51:860-872.

PRI (2019) A practical guide to ESG integration in sovereign debt.

Ricke K, Drouet L, Caldeira K, Tavoni M (2018) Country-level social cost of carbon. Nature Climate Change. S\&P (2018) How Environmental, social, and governance factors help shape the ratings on governments, insurers, and financial institutions. October 23, 2018.

S\&P (2017) Sovereign rating methodology. December 18, 2017. November 25, 2015.

$\mathrm{S} \& \mathrm{P}$ (2015a) The heat is on: How climate change can impact sovereign ratings. November 25, 2015.

S\&P (2015b) Storm Alert: Natural disasters can damage sovereign creditworthiness. September 10, 2015.

Stern N (2008) The economics of climate change. American Economic Review. 98:1-37.

TCFD (2020) Task force on climate-related financial disclosures: 2020 status report. Financial Stability Board.

TCFD (2017) Recommendations of the task force on climate-related financial disclosures. Financial Stability Board.

Van Gestel, T., Martens D, Baesens B, Faremans D, Huysmans J, Vanthienen J (2007) Forecasting and analyzing insurance companies' ratings. International Journal of Forecasting. 23:513-529.

Van Gestel T, Baesens B, Van Dijcke P, Garcia J, Suykens AKJ, Vanthienen J (2006) A process model to develop an internal rating system: sovereign credit ratings. Decision Support Systems. 42:1131-1151.

van Vuuren D, Edmonds J, Kainuma M, Riahi K, Thomson A, Hibbard K, Hurtt G, Kram T, Krey V, Lamarque JF, Masui T, Meinshausen M, Nakicenovic N, Smith S, Rose S (2011) The representative concentration pathways: An overview. Climatic Change. 109:5-31.

Wager S, Hastie T, Efron B (2014) Confidence intervals for random forests: The jackknife and the infinitesimal jackknife. The Journal of Machine Learning Research. 15:1625-1651.

Zenghelis D, Manley A, Wdowin J (2020) Public debt, public wealth and economic dynamics. Cambridge, UK. 


\section{Appendices}

\section{Appendix A- Literature review}

Assessing the effect of climate change on sovereign ratings is an inherently interdisciplinary endeavour. We combine several strands of scientific and economic research with practitioner insights from the world of sovereign ratings. This section introduces key themes from climate economics, sovereign risk assessment, and machine learning that underpin our study.

\section{Climate-economy models}

Macroeconomic climate models can be grouped into two categories: global integrated assessment models (IAMs) such as the DICE model for which Bill Nordhaus was awarded the 2018 Nobel Prize in Economics (for reviews, see Aufhammer 2018; Diaz \& Moore 2017), and a more recent strand of macroeconometric models to estimate the long-run impacts of changes in temperature and precipitation of aggregate output at the country level (Burke et al., 2015; Dell et al., 2014; Kahn et al., 2019). IAMs typically operate at the global scale and are used to evaluate economic impacts of various warming scenarios or climate policies, or to calculate the social cost of carbon for use in social cost-benefit analyses (Stern 2008). Although they have been useful in organising economists' thinking about climate-economic relationships, IAMs are notoriously sensitive to assumptions about discount rates, the shape and parameterisation of damage functions, the latency of greenhouse gases in the atmosphere, the degree of climate sensitivity, and the costs and efficacy of investments in mitigation and adaptation (Aufhammer 2018; Diaz \& Moore 2017). Whilst some characterize such sensitivities as weaknesses (Pindyck 2013), others find their flexibility useful for integrating advances in economic theory and environmental science into climate policy (Bastien-Olvera \& Moore 2020; Dietz \& Stern 2015).

The primary limitation of IAMs for the current application - assessing the effect of climate on sovereign creditworthiness - is their high degree of spatial aggregation. Global analyses do not easily translate into country-level risk metrics. ${ }^{19}$ For instance, using DICE, Dietz et al. (2016) estimate the representative 'climate value at risk' of global financial assets to be US \$2.5 trillion, but do not comment on the distribution of value at risk across countries. While their

\footnotetext{
${ }^{19}$ Even the regional version of DICE (called RICE), aggregates to eight regions (Nordhaus \& Boyer 2000).
} 
results demonstrate that restricting warming to $2^{\circ} \mathrm{C}$ or less make financial sense for risk-neutral and institutional investors, DICE prevents them from making statements about sovereign risk.

A new body of research is emerging that combines climate science with long-run macroeconometric analyses of relationships between temperature and GDP growth at the country-level (Burke et al., 2015; Dell et al., 2012, 2014; Kahn et al., 2019). Such models are increasingly used to assess country-level impacts of climate change and identify countryspecific social costs of carbon (Ricke et al., 2018). In an early contribution, Dell et al. (2012) constructed a 53-year, 125 country panel of weather and macroeconomic data to show that warming significantly reduces growth in poor countries by 1.3 percentage points for each $1 \mathrm{C}$ increase in temperature, but that the results are not significant in rich countries. Relaxing Dell et al's (2012) assumption of linearity, Burke et al. (2015) find more extreme and unequal values for the impacts of climate change, with substantial winners and losers from climate change, summing to a net $22.6 \%$ of gross world product by 2100 . Whilst these models can produce estimates of the economic effects of climate change, their macro structure means they cannot comment on the mechanisms through which these impacts are found (Burke et al., 2015). In contrast, Kahn et al., (2019) develop a stochastic growth model that links deviations of countryspecific climate variables (temperature and precipitation) from their historical norms to real output per capita growth. Using data between 1960 and 2014 and 174 countries, they find that persistent deviations of temperature from time-varying and country-specific historical thresholds (i.e., the historical norm) reduces per capita output growth, amounting to around 7\% reduction in gross world product by 2100 in the absence of mitigation policies (with the global losses being significantly higher at $13 \%$ if the country-specific variability of climate conditions were to rise commensurate to temperature increases). Due to their ability to assess countrylevel climate impacts (and explicitly modelling changes in the distribution of weather patterns; that is not only averages of climate variables that the climate-macro literature focuses on but also their variability), our baseline model uses Kahn et al., (2019) to inform our assessment of the effects of climate change on sovereign ratings, and Burke et al., (2019) for a robustness check.

To facilitate interpretation and comparability, climate modelling exercises refer to a common set of future scenarios called representative concentration pathways (RCPs). RCPs describe potential trajectories for the annual flow and overall stock of greenhouse gases (GHGs), 
aerosols, and chemically active gases in the atmosphere to 2100 (Moss et al., 2010). Each RCP is named according to its corresponding level of radiative forcing in 2100 . For instance, RCP 2.6 refers to a world of stringent climate policy that results in an end-of-century increase in radiative forcing of $2.6 \mathrm{Watts} / \mathrm{m} 2$ and corresponds to temperature rise well below $2^{\circ} \mathrm{C}$, relative to pre-industrial conditions. In contrast, RCP 8.5 refers to an end-of century increase in radiative forcing $(8.5 \mathrm{Watts} / \mathrm{m} 2)$ and temperature of $5^{\circ} \mathrm{C}$, relative to pre-industrial levels.

In terms of policy, the Paris Climate Agreement pledged to limit average warming to 'well below $2^{\circ} \mathrm{C}^{\prime}$ and corresponds most closely to RCP 2.6. In contrast, RCP 8.5 is described as the 'worst case' high emissions scenario (Hausfather \& Peters 2020; van Vuuren et al., 2011). For comparability with previous literature, we report results for warming scenarios under RCP 2.6 and RCP 8.5.

\section{Climate change and sovereign credit risk}

To the best of our knowledge, there is no previous climate science-driven economic analysis of the impact of future climate change related to all types of climate weather events on sovereign ratings. The closest, papers are S\&P (2015a,b) and Cevik \& Jalles (2002a). In S\&P (2015b) authors convert the economic outcomes resulting from extreme weather conditions into simplified sovereign rating tool. Findings suggest amongst studied perils earthquakes are the most devastating natural hazard and will likely to put pressure on creditworthiness of sovereigns close to the "edges of Earth's geological plates" such as Chile, Costa Rica, Japan, Panama Peru, Philippines, Taiwan. S\&P (2020a) is based on sample of 38 sovereigns and 44 natural catastrophe events arising due to two perils: tropical cyclones and floods. To quantify climate change impact for each sovereign, the authors simulate direct damage to property and infrastructure resulting from given disaster type. The benchmark severity is a natural disaster that would be expected to occur once in every 250 years using a probabilistic model 250 years being a standard benchmark in the reinsurance industry). Simulated impacts take a time horizon up to 2050, and suggest that the impact of climate change via natural disasters is more important for emerging and developing sovereigns than for the advanced economies. Our results vary significantly which might be driven the fact we apply climate-economy models which take account of all natural perils and study much larger sample of sovereigns around the globe. Our trajectories also differ significantly as we are able to predict the climate-adjuested ratings for the years up to 2100 . 
Offering a backward look rather a future simulation of sovereign ratings Cevik \& Jalles (2020a) use OLS and ordered response models to regress past sovereign ratings on climate vulnerability, resilience, and the usual macroeconomic indicators for a panel of 67 countries between 1995 and 2017. They find a positive statistically significant effect of climate resilience on ratings, but only mixed results for vulnerability. We advise caution in interpreting these results for several reasons. Many of the countries ${ }^{20}$ in their sample were not rated by CRAs until the mid-2000s and may not have many ratings events in the panel. Moreover, the effect of climate change over the period 1995 - 2017 is likely to be small compared to what is expected over the coming century. It could be difficult to identify climate-specific impacts on ratings in the past. More importantly, their approach only considers the effects of climate change on ratings through climate vulnerability and resilience, but ignores the effect of climate change on GDP per capita, GDP growth, or indeed any of the other macroeconomic variables in their model. Finally, we present a number of econometric and methodological challenges in the next section.

Most of the literature on climate and sovereign risk focuses on bond yields rather than ratings (Beirne et al., 2020; Buhr et al., 2018; Capelle-Blancard et al., 2017; Cevik \& Jalles 2020b,c; Crifo et al., 2015; Kling et al., 2018). An increasingly common finding is that high climate vulnerability and low resilience increases sovereign borrowing costs, especially for lower income countries (Beirne et al., 2020; Kling et al., 2018). Calculating the impact of climate risk on bond yields for 46 countries from 1996 to 2016, Buhr et al. (2018) find that climate related vulnerability increased the cost of debt of developing countries by 117 basis points, which translates into USD 40 billion in additional interest payments on government debt over the period of past 10 years.

Recent research also suggests exposure to climate risk increases public borrowing costs in developed countries. Painter (2020) investigates how exposure to sea level rise affects yields for US municipalities, finding that a one percent increase in climate risk leads to an increase in cost of capital by 23.4 basis points, or an average rise in annualized issuance costs of $\$ 1.7$ million for the average county (Painter 2020).

\footnotetext{
${ }^{20}$ For instance, Albania's first ever rating was in 2010, Azerbaijan 2008, Bosnia 2008, Fiji 2006, Gabon 2007, Georgia 2005, Mozambique 2004, Nigeria 2006, Seychelles 2006.
} 


\section{Estimating sovereign ratings}

As key intermediaries between the supply and demand for finance, credit ratings agencies (CRAs) play a central role in markets by providing standardised information about the creditworthiness of investments. Sovereign ratings compile objective data with subjective assessments of the ability and willingness of sovereigns to service their debt. Although CRAs make their ratings methodologies publicly available, ${ }^{21}$ the subjective inputs mean that sovereign ratings are not perfectly replicable by outsiders. ${ }^{22}$ For this reason, a literature has arisen to try to 'hack' the sovereign ratings methods, using publicly available macroeconomic and governance indicators to 'reconstruct' sovereign ratings based on objective data, thus eliminating the subjective component and making ratings replicable.

Traditional approaches to modelling credit ratings often rely on parametric estimation (see for example, Afonso et al., 2009; 2011; Baghai et al., 2016; Cantor \& Packer 1996). Most often this is an ordered probit model, featuring alongside other methodologies as robustness checks including linear regression and logit regression (see Cevik \& Jalles 2020a). However, the uniqueness of credit ratings presents several challenges. First, ratings are inherently non-linear. Incremental shifts through the rating scale do not represent equally meaningful changes in credit worthiness. For instance, if Country A moves from one high grade rating to another, this change would not be as significant as if Country A moved from a lower medium grade to a non-investment grade. Second, sovereign credit ratings are not characterised by the same distributional properties we may observe in other variables. The case is that often far more observations are found at the top-end of the ratings scale than throughout the rest of the rating categories. These features make linear modelling of credit ratings difficult and subsequently lead to error. The methodologies used in the literature may also be subject to other errors, such as multi-collinearity. This is often induced as a result of collinear predictors in country level data or using least-squares dummy variable (LSDV) estimations.

Motivated by these issues, researchers have considered non-parametric approaches to modelling sovereign ratings. Methodological implementations are varied, which include the application of artificial neural networks (Bennell et al., 2006; Fioramanti 2008; Markellos et

\footnotetext{
${ }^{21}$ For a graphical interpretation of S\&P sovereign methodology see Figure A.1.

${ }^{22}$ One of our authors Global Chief Rating Officer, Sovereign Ratings at S\&P (2013 - 2018).
} 
al., 2016), decision trees (Markellos et al., 2016), random forests (Ozturk et al., 2016; De Moor et al., 2018) and support vector machines (Van Gestel et al., 2007). The central benefits associated with these approaches are twofold. First, nonparametric approaches are much better at handling non-linear outcomes in the data (Markellos et al., 2016). Second, these approaches can often provide a superior fit (De Moor 2018). In addition, it is suspected that sovereign credit ratings are subject to certain thresholds in various country level predictors, such as GDP per capita (S\&P 2017). Therefore, using methodologies that are capable of handling nonlinearities is essential.

Random forest algorithms are variously identified as the optimum machine learning technique in the application of credit rating prediction (Ozturk et al., 2016; De Moor et al., 2018). Figure A. 2 provides an overview of the mechanics of this algorithm. Random forests are most intuitively thought of as a collection of decision trees. Decision tree algorithms work through the construction a series of nodes represented by the circles in Fig. A.2. At each node the algorithm selects the feature which provides the best split of the data. Once the data has been split on the first feature, it then attempts to split the data again such that the resulting splits are as different from the other split as possible, but as similar to each other as possible. This process continues until the data can no longer be split on the features provided.

Random forest algorithms can be thought of as extensions of decision trees, and are different in two key ways. First, decision tree algorithms can be highly sensitive to the data on which they have been trained. Random forests improve upon this by enabling each tree within the forest to be trained upon a randomly selected sub-sample of the data, with replacement. Second, in an ordinary decision tree process, the algorithm selects the feature (from all available features) which provides the best split. A random forest algorithm enables the tree to select from only a random subset of features. The intuition behind each of these two modifications is that the prediction made by a forest is an average of the decision made by each tree, and as a consequence is much more reliable and robust as a collection.

Machine learning methodologies are becoming increasingly popular in the sovereign ratings literature. Research variously employs these techniques to model the impact of the informal economy (Markellos et al., 2016), predict sovereign debt crises (Fioramanti 2008), provide accurate predictions of credit ratings (Bennell, 2006; De Moor et al., 2018; Ozturk et al., 2016; Van Gestel et al., 2006) and explain variance in ESG ratings (Berg et al., 2020). Evidence 
across the literature supports the view that machine learning techniques outperform traditional parametric approaches in each of these applications. Furthermore, in applications of rating prediction, research reports an improvement of accuracy of approximately $30 \%$ above parametric approaches (De Moor et al., 2018; Ozturk et al., 2016). This research supports the use of random forest techniques in ratings prediction application.

This paper differs from the existing literature in one primary way. That is, our goal is to estimate sovereign credit ratings in various climate change scenarios. A common theme throughout the literature is the inclusion of a wide range of determining variables. Inclusive amongst these are economic indicators, trade relations, and measures of institutional quality. In our application we only make use of variables which we can readily predict under climate change scenarios. As such, we sacrifice some predictive capacity in order to stay as close to the climate research as possible.

Since some of the metrics are not quantifiable and due to proprietary rights weights of the exact (numerous) variables are not known it is difficult to closely replicate the rating. Because sovereign debt has a pronounced economic and financial effect many researchers attempted to find an exhaustive suite of sovereign rating determinants using publicly available information to then mimic and forecast them into the future.

Figure A.1. S\&P's sovereign ratings methodology

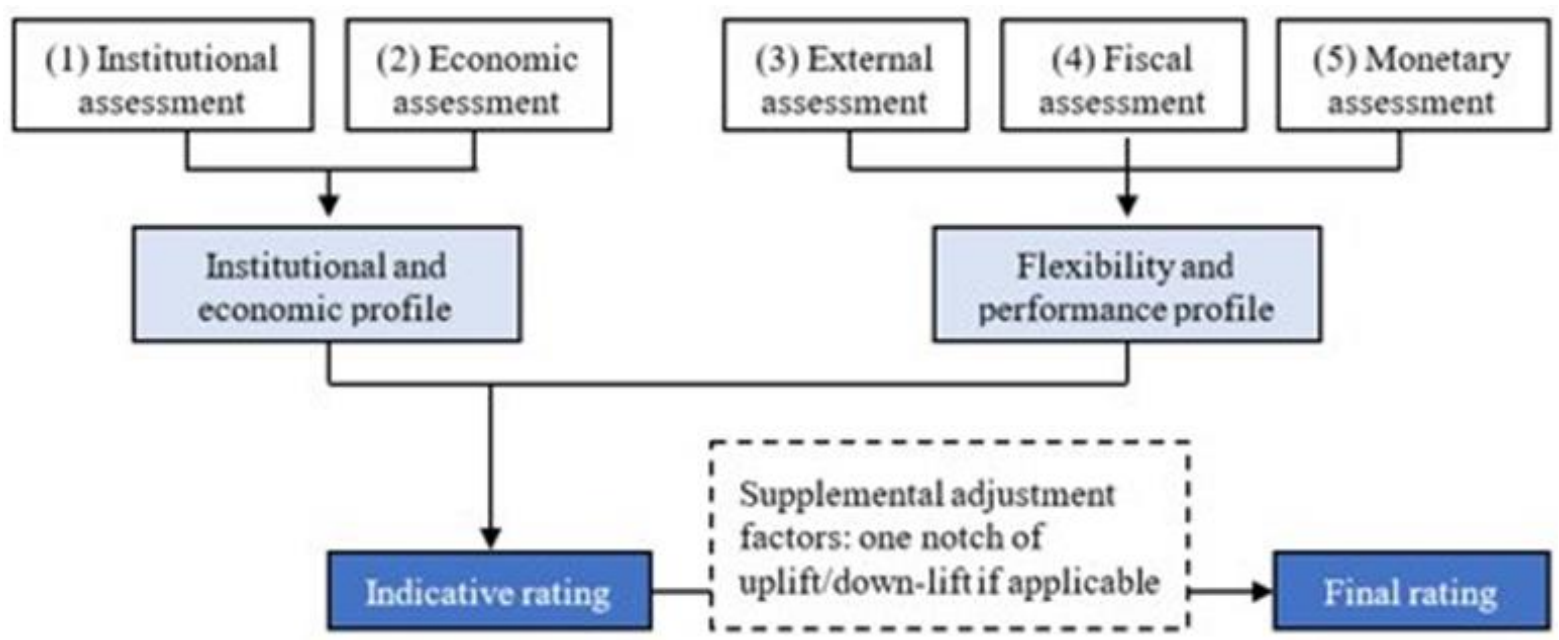

Source: S\&P (2017) 


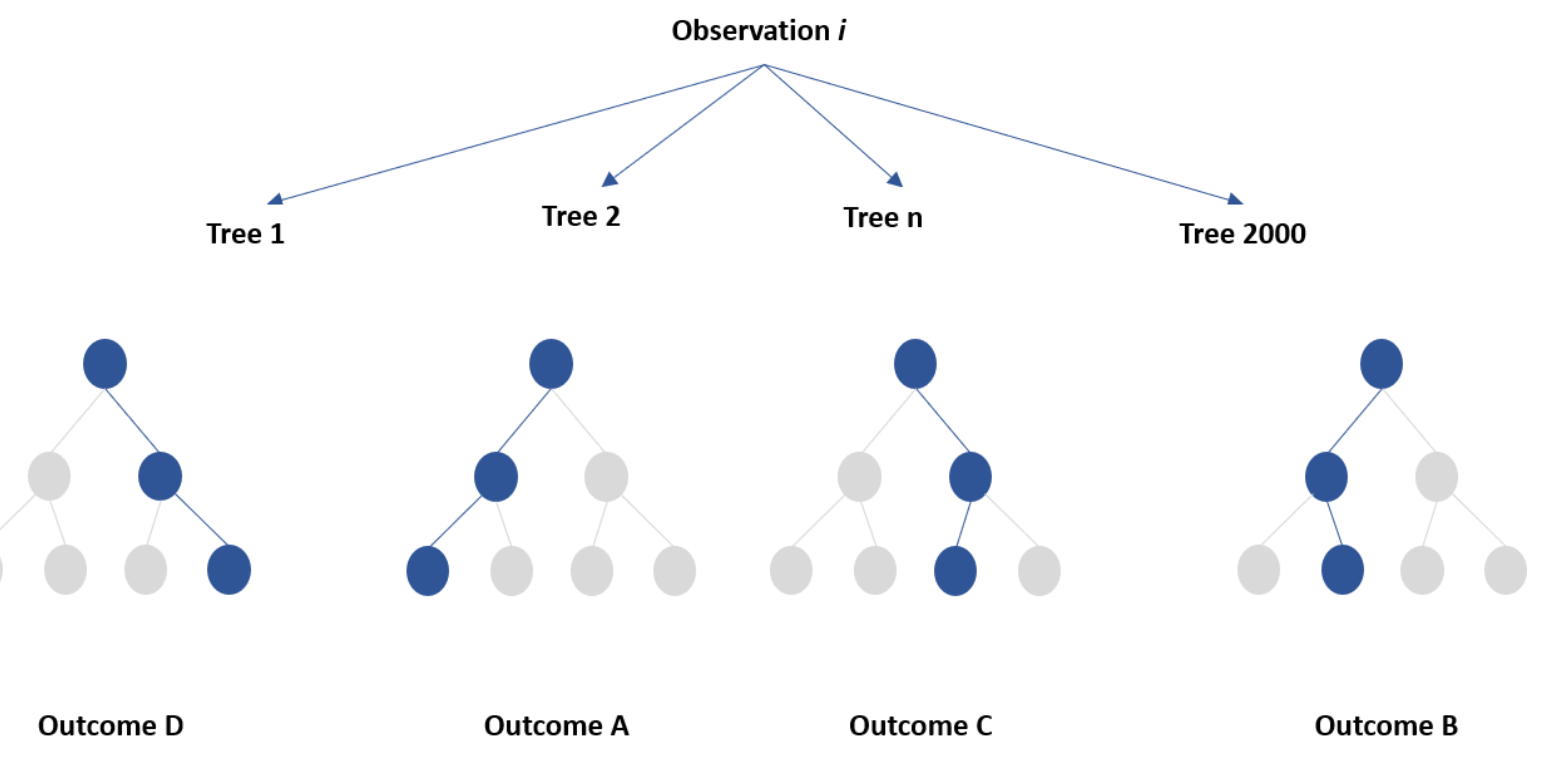

\section{Appendix B- Data and methodology}

\section{B.1. Constructing climate-adjusted government balance variables}

To construct climate-adjusted versions of the four government balance variables in our model, we extrapolate statistical models based on data from S\&P (2015b). S\&P produce estimates of the effect of various climate and natural disasters on our set of government balance indicators. For instance, using the scenario of a 1 in 250 - year earthquake, they estimate the damage caused, impacts on GDP per capita. They repeat this analysis for tropical cyclones, floods and winter storms. To make use of this data, we combine the tables in S\&P (2015b) and assume homogeneity across the various events.

Figure B.1. illustrates the process. Data points combines values from tables in S\&P (2015b) describing the relationship between disaster-induced losses in per capita GDP and the log of net general government debt (one of our four government performance variables). To adjust our government performance variables for the effect of climate change, we need a function describing the data in Figure B.1. To derive this function, we first fit a linear model (red line), followed by polynomials of increasing order until ANOVA tests indicate no further significance is achieved. Using the coefficients from the best fit polynomial, we apply GDP 
losses determined by Kahn et al. (2019) to derive climate-adjusted net general government debt for each country in the sample. We repeat the process for each government balance variable.

Figure B.1. Fitting models of the effect of GDP loss on government performance variables

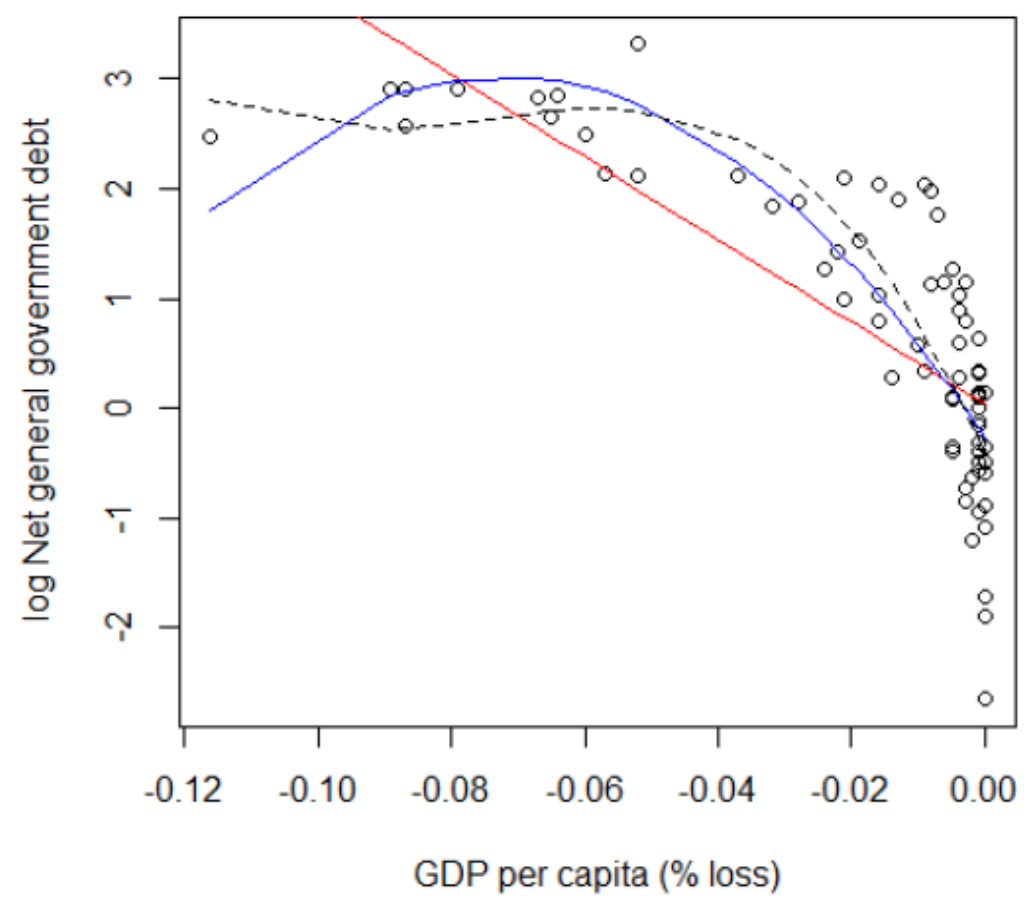

This approach is a simplification, as more sophisticated models of the effects of each type of disaster on GDP may be available. However, we believe this is justified for two reasons. First, in this step we are not interested in the effect of disasters on GDP, but rather the effect of the change in GDP on e.g. net general government debt. Our measure of the effect of climate on GDP comes directly from Kahn et al. (2019). Second, this approach provides practitioner evidence on the expected relationship between GDP losses and these macro indicators, keeping our approach as close as possible to real-world practice in CRAs. Finally, the approach enables us to continue to rely on the same direct links between climate science and climate economics that we use for adjusting GDP and its growth rate. 
Table B.1. Converting S\&P's sovereign ratings to a 20-notch numerical scale

\begin{tabular}{|c|c|c|c|}
\hline $\begin{array}{c}\text { Long-term } \\
\text { foreign currency }\end{array}$ & Numerical rating & \multicolumn{2}{|c|}{ Rating grade } \\
\hline AAA & 20 & Prime high grade & \multirow{10}{*}{ Investment grade } \\
\hline $\mathrm{AA}+$ & 19 & \multirow{3}{*}{ High grade } & \\
\hline $\mathrm{AA}$ & 18 & & \\
\hline AA- & 17 & & \\
\hline $\mathrm{A}+$ & 16 & \multirow{3}{*}{ Upper medium grade } & \\
\hline A & 15 & & \\
\hline A- & 14 & & \\
\hline $\mathrm{BBB}+$ & 13 & \multirow{3}{*}{ Lower medium grade } & \\
\hline BBB & 12 & & \\
\hline BBB- & 11 & & \\
\hline $\mathrm{BB}+$ & 10 & \multirow{3}{*}{ Speculative } & \multirow{12}{*}{ Non-investment grade } \\
\hline $\mathrm{BB}$ & 9 & & \\
\hline BB- & 8 & & \\
\hline $\mathrm{B}+$ & 7 & \multirow{3}{*}{ Highly speculative } & \\
\hline $\mathrm{B}$ & 6 & & \\
\hline B- & 5 & & \\
\hline $\mathrm{CCC}+$ & 4 & \multirow{3}{*}{ Substantial risks } & \\
\hline $\mathrm{CCC}$ & 3 & & \\
\hline CCC- & 2 & & \\
\hline $\mathrm{CC}$ & 1 & \multirow{2}{*}{ Extremely speculative } & \\
\hline $\mathrm{C}$ & 1 & & \\
\hline $\mathrm{D} / \mathrm{SD}$ & 1 & In default & \\
\hline
\end{tabular}

Notes: This table presents S\&P alphabetical categories translated into 20-notch scale based on S\&P's Global Rating Definitions available from:

https://www.standardandpoors.com/en_US/web/guest/article///view/sourceId/504352 


\section{Appendix C - Robustness to alternative climate-economy models and longer time series}

We employ several approaches to testing the robustness of our results. First, we extend the time series of ratings data used to train our ratings prediction model. Our baseline model is trained on 639 sovereign rating actions issued by S\&P between 2015 and 2020. This time series is chosen because it overlaps with data outputs (climate-adjusted GDP) from our climateeconomy model (Kahn et al., 2019) and because ratings issued at any point within this timeframe are still within the standard ratings horizon of 5-10 years. ${ }^{23}$ However, most of the countries in our sample have ratings histories that pre-date our 2015 cut-off, meaning a longer time series is available.

To test our model on a longer time series of sovereign ratings, we incorporated data on S\&P's sovereign ratings between 2004 and 2020. Tripling the timespan more than doubles our observations number from 639 in the baseline to 1385 in the extended sample. We train the same 6-variable model on the same 108 countries. Table C.1. compares predictive accuracy of our baseline model (columns 2-4) against our extended time series model (columns 5-7). Extending the ratings sample reduces exact matches between observed ratings and our predictions for in-sample, out of sample, and out of sample investment grade ratings. However, this is a random model and variation in predictive accuracy of this magnitude are observed across multiple runs of the model. Interestingly, extending the time series has opposite effects on the accuracy of out of sample tests when we run the model on the full set of 108 countries compared to restricting it to countries with investment grade ratings. Focusing on all 108 countries (columns 2 and 5), we see a decrease in predictive accuracy across the board. In contrast, focusing only on those countries with investment grade ratings (columns 4 and 7), we see slight reduction in exact matches followed by improved accuracy within 1,2, and 3 notches.

\footnotetext{
${ }^{23}$ At the time of writing.
} 
Table C.1. Predictive accuracy with an extended time series

\begin{tabular}{|c|c|c|c|c|c|c|}
\hline \multirow[b]{2}{*}{ Rating range } & \multicolumn{3}{|c|}{ Our results $(2015-2020)$} & \multicolumn{3}{|c|}{ Extended sample $(2004-2020)$} \\
\hline & $\begin{array}{l}\text { Whole } \\
\text { Sample }\end{array}$ & $\begin{array}{c}\text { Out of } \\
\text { sample } \\
(80 / 20 \\
\text { split })\end{array}$ & $\begin{array}{c}\text { Investment } \\
\text { Grade Out } \\
\text { of Sample } \\
(80 / 20)\end{array}$ & $\begin{array}{l}\text { Whole } \\
\text { Sample }\end{array}$ & $\begin{array}{c}\text { Out of } \\
\text { sample } \\
(80 / 20 \\
\text { split })\end{array}$ & $\begin{array}{c}\text { Investment } \\
\text { Grade Out } \\
\text { of Sample } \\
(80 / 20)\end{array}$ \\
\hline Exact match & $67.92 \%$ & $31.75 \%$ & $34.78 \%$ & 55.45 & 28.52 & 28.40 \\
\hline 1 notch & $96.24 \%$ & $76.19 \%$ & $63.77 \%$ & 92.56 & 63.18 & 71.60 \\
\hline 2 notch & $99.69 \%$ & $90.48 \%$ & $81.16 \%$ & 98.41 & 81.85 & 88.76 \\
\hline 3 notch & - & $94.44 \%$ & $92.75 \%$ & 99.57 & 91.70 & 97.63 \\
\hline Observations & 639 & $513 / 126$ & $276 / 69$ & 1385 & 1108 & 672 \\
\hline \# of variables & 6 & 6 & 6 & 6 & 6 & 6 \\
\hline Countries & 108 & 108 & $62 / 42$ & 108 & 108 & 66 \\
\hline
\end{tabular}

Notes: Table presents the predictive capacity of our benchmark random forest model, and an extended time series. Columns 2-4 present the results also found in Table 3. Columns 5-7 present the results when the model is trained on an extended time period.

At first, these results may seem counterintuitive: more data can typically be expected to improve accuracy. However, several unique features of sovereign ratings suggest this may not be the case. First, sovereign ratings have an informal 'lifespan' of 5-10 years, owing to the fact that the political and economic factors on which ratings are based may change substantially over this timeframe. Thus, the inclusion of obsolete data may not improve current predictions. Perhaps more importantly, our extended time series now includes the build-up, duration, and aftermath of the 2008 financial crisis. This was a turbulent period for sovereign ratings and fiscal conditions world-wide. As such, the extended time series may actually introduce more noise than predictive capacity. Finally, results in terms of the simulated impacts of climate change on sovereign ratings were not qualitatively different when the timespan was extended. ${ }^{24}$ Thus, for our baseline scenario we focus on ratings issued between 2015 and 2020.

One potential concern with our results is that they could be sensitive to the choice of underlying climate-economic model (clear box in Figure 1). Models in the macroeconometric climate literature employ a range of econometric assumptions and specifications, sometimes leading to substantially different conclusions. To assess the sensitivity of our results to the choice of model, we ran the full exercise again using Burke et al. (2015) rather than Kahn et al. (2019)

\footnotetext{
${ }^{24}$ Figures and tables can be provided upon request.
} 
for the underlying impacts of climate on GDP and government balances. Compared to Kahn et al. (2019), Burke et al. (2015) find more extreme and unequal results across countries. For instance, they find that due to climate change, India will face a $92 \%$ reduction in per capita GDP by 2100 , whereas Iceland will face a $513 \%$ increase.

Both the depths of the modelled losses in hot countries and the peaks of the modelled gains among Northern countries remain outliers in the literature and present challenges for our model. Due to the importance of per capita GDP and its growth rate for simulating ratings, Burke et al.'s extreme results create a larger number of climate-induced upgrades, largely concentrated at the lower end of the ratings scale. Moreover, our interpolative method for extracting the climate-adjusted government balance indicators is less reliable in this setting. S\&P (2015b) only assessed the effect of GDP losses of up to $12 \%$ on our government performance variables, but Burke et al.'s estimated per capita GDP losses often exceeded this range substantially (e.g., for India, they predict losses of 92\%). To avoid extrapolating beyond S\&P's data, we capped the negative impacts at $12 \%$ GDP loss, and positive impacts at $0 \%$ gains. Finally, to maximise our predictive capacity in the face of Burke et al.'s extreme impacts, we restricted our analysis to investment-grade sovereigns.

Figure C.2. Panels A and B illustrate the effect of climate change on investment-grade sovereigns for the year 2100 under Burke et al.'s warming and no warming scenario. Panel A shows that although the results are clearly noisier than under our baseline model using Kahn et al. (2019), we find a similar pattern of substantial downgrades, with greater reductions at the higher end of the scale. T-tests indicate the results are statistically significantly different from zero at the $1 \%$ level. Similarly, Panel B depicts our predicted changes in ratings for 2100 (again for investment-grade countries only) using the 'no climate change' scenario from Burke et al.'s model. These results show much closer alignment with current observed ratings. T-tests indicate the changes cannot be statistically significantly distinguished from zero. 
Figure C.2. Effect of climate on ratings (2100, RCP 8.5 vs no warming scenario)
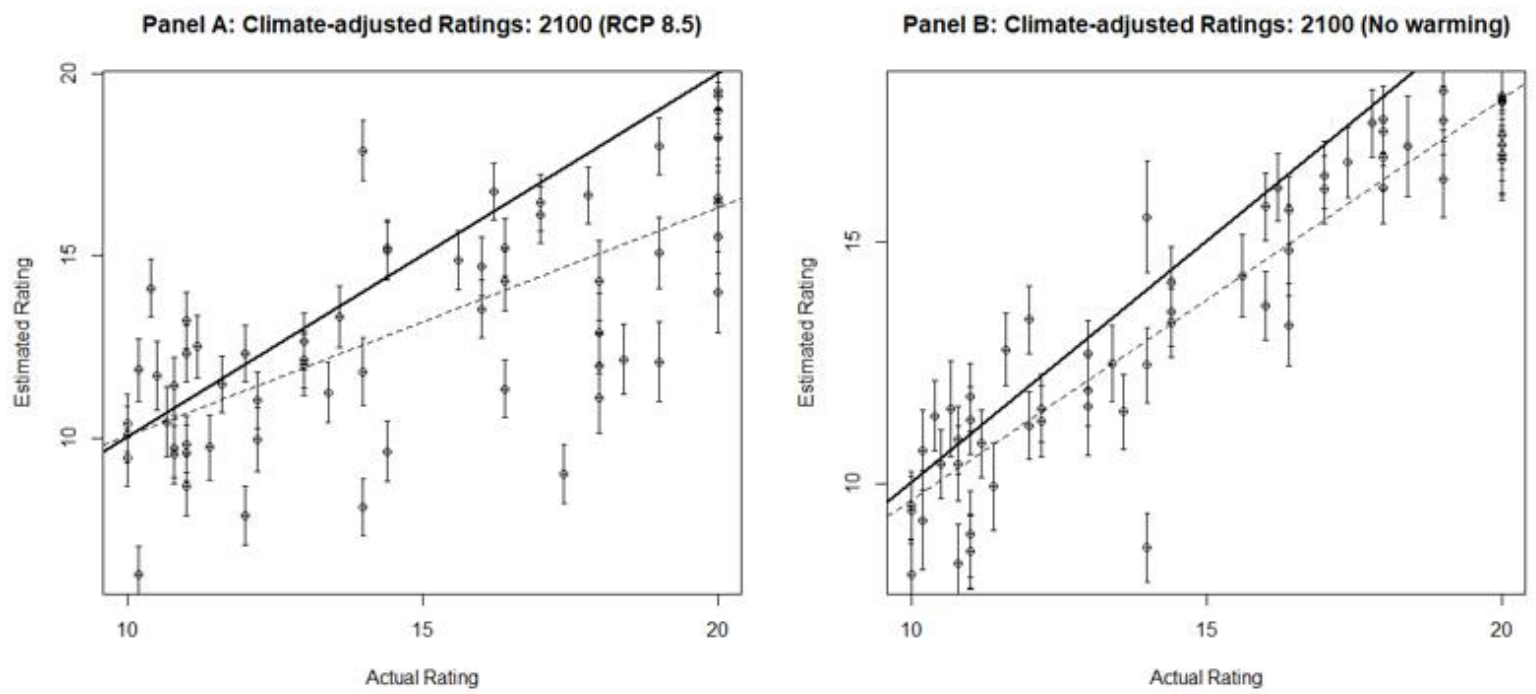

Notes: Estimates based on climate economy model of Burke et al. (2015). 
Appendix D - Additional cost of sovereign and corporate borrowing due to climateinduced sovereign downgrades

Table D.1. Additional cost of sovereign borrowing due to climate-induced sovereign downgrades (RCP 2.6, 2100)

\begin{tabular}{|c|c|c|c|c|}
\hline Sovereign & $\begin{array}{c}\text { Outstanding } \\
\text { sovereign } \\
\text { debt }(\$ \text { bn }) \\
\end{array}$ & $\begin{array}{c}\text { Sovereign } \\
\text { downgrade } \\
\text { (notches) }\end{array}$ & $\begin{array}{c}\text { Cost of sovereign } \\
\text { borrowing ( } \$ \text { bn) } \\
\text { (lower bound) }\end{array}$ & $\begin{array}{c}\text { Cost of sovereign } \\
\text { borrowing (\$ bn) } \\
\text { (higher bound) }\end{array}$ \\
\hline Australia & 384.50 & 1.09 & 0.33 & 0.50 \\
\hline Austria & 231.70 & 1.16 & 0.22 & 0.32 \\
\hline Bangladesh & 45.50 & 0.36 & 0.01 & 0.02 \\
\hline Belgium & 436.90 & 0.52 & 0.18 & 0.27 \\
\hline Benin & 3.90 & 0.21 & 0.00 & 0.00 \\
\hline Botswana & 1.10 & 0.91 & 0.00 & 0.00 \\
\hline Bulgaria & 10.80 & 0.19 & 0.00 & 0.00 \\
\hline Canada & 557.10 & 0.58 & 0.26 & 0.39 \\
\hline Chile & 70.50 & 2.56 & 0.14 & 0.22 \\
\hline China & 2464.40 & 2.05 & 4.03 & 6.05 \\
\hline Colombia & 129.80 & 1.39 & 0.14 & 0.22 \\
\hline Costa Rica & 31.40 & 0.68 & 0.02 & 0.03 \\
\hline Czechia & 70.20 & 0.73 & 0.04 & 0.06 \\
\hline $\begin{array}{l}\text { Denmark } \\
\text { Dominican }\end{array}$ & 91.70 & 0.66 & 0.05 & 0.07 \\
\hline Republic & 28.70 & 0.07 & 0.00 & 0.00 \\
\hline Estonia & 0.10 & 0.39 & 0.00 & 0.00 \\
\hline Finland & 118.10 & 0.48 & 0.05 & 0.07 \\
\hline France & 2026.10 & 0.83 & 1.35 & 2.02 \\
\hline Georgia & 2.60 & 0.4 & 0.00 & 0.00 \\
\hline Germany & 1254.30 & 0.23 & 0.23 & 0.34 \\
\hline Honduras & 6.80 & 0.03 & 0.00 & 0.00 \\
\hline India & 1365.30 & 1.47 & 1.61 & 2.41 \\
\hline Indonesia & 290.60 & 0.91 & 0.21 & 0.32 \\
\hline Israel & 237.90 & 0.17 & 0.03 & 0.05 \\
\hline Japan & 10396.20 & 0.36 & 2.96 & 4.44 \\
\hline Jordan & 29.50 & 0.13 & 0.00 & 0.00 \\
\hline Kazakhstan & 26.80 & 0.61 & 0.01 & 0.02 \\
\hline Kenya & 37.00 & 0.58 & 0.02 & 0.03 \\
\hline South Korea & 589.50 & 0.65 & 0.31 & 0.46 \\
\hline Kuwait & 16.50 & 0.45 & 0.01 & 0.01 \\
\hline Latvia & 11.20 & 0.3 & 0.00 & 0.00 \\
\hline Luxembourg & 11.70 & 0.11 & 0.00 & 0.00 \\
\hline Malaysia & 189.80 & 0.71 & 0.11 & 0.16 \\
\hline Mexico & 386.40 & 0.55 & 0.17 & 0.26 \\
\hline
\end{tabular}




\begin{tabular}{|c|c|c|c|c|}
\hline \multicolumn{5}{|c|}{ Table D.1. Continued } \\
\hline Sovereign & $\begin{array}{c}\text { Outstanding } \\
\text { sovereign } \\
\text { debt }(\$ \text { bn }) \\
\end{array}$ & $\begin{array}{c}\text { Sovereign } \\
\text { downgrade } \\
\text { (notches) }\end{array}$ & $\begin{array}{c}\text { Cost of sovereign } \\
\text { borrowing }(\$ \text { bn) } \\
\text { (lower bound) }\end{array}$ & $\begin{array}{c}\text { Cost of sovereign } \\
\text { borrowing (\$ bn) } \\
\text { (higher bound) }\end{array}$ \\
\hline Morocco & 67.20 & 1.52 & 0.08 & 0.12 \\
\hline Netherlands & 341.40 & 0.37 & 0.10 & 0.15 \\
\hline New Zealand & 52.70 & 0.46 & 0.02 & 0.03 \\
\hline Macedonia & 4.00 & 0.21 & 0.00 & 0.00 \\
\hline Norway & 49.80 & 0.34 & 0.01 & 0.02 \\
\hline Panama & 23.60 & 0.57 & 0.01 & 0.02 \\
\hline Peru & 49.10 & 1.11 & 0.04 & 0.07 \\
\hline Philippines & 134.50 & 0.73 & 0.08 & 0.12 \\
\hline Poland & 222.40 & 0.66 & 0.12 & 0.18 \\
\hline Qatar & 100.20 & 0.28 & 0.02 & 0.03 \\
\hline Senegal & 6.00 & 0.14 & 0.00 & 0.00 \\
\hline Serbia & 14.30 & 0.49 & 0.01 & 0.01 \\
\hline Slovakia & 42.90 & 0.89 & 0.03 & 0.05 \\
\hline Slovenia & 31.00 & 0.59 & 0.01 & 0.02 \\
\hline South Africa & 213.30 & 0.72 & 0.12 & 0.18 \\
\hline Sri Lanka & 57.20 & 0.13 & 0.01 & 0.01 \\
\hline Sweden & 119.70 & 0.92 & 0.09 & 0.13 \\
\hline Switzerland & 68.60 & 0.84 & 0.05 & 0.07 \\
\hline Thailand & 180.20 & 0.59 & 0.08 & 0.13 \\
\hline United Kingdom & 2710.70 & 0.92 & 2.00 & 3.00 \\
\hline United States & 16673.40 & 0.55 & 7.35 & 11.03 \\
\hline Full sample total & 42716.80 & 0.65 & 22.74 & 34.11 \\
\hline
\end{tabular}

Notes: Translating climate-induced sovereign downgrades into increased sovereign cost of borrowing by 2100 under RCP 2.6 scenario. Dataset includes 55 downgraded sovereigns and their outstanding sovereign debt figures for 2019 obtained from S\&P SRIs. Conversion between sovereign downgrades into yields for lower bound is based on Afonso et al. (2012) and for higher bound on Gande \& Parsley (2005), whereby 1 notch sovereign downgrade increases sovereign bond spread by $0.08 \%$ and $0.12 \%$ respectively. 
Table D.2. Additional cost of sovereign borrowing due to climate-induced sovereign downgrades (RCP 8.5, 2100)

\begin{tabular}{|c|c|c|c|c|}
\hline Sovereign & $\begin{array}{c}\text { Outstanding } \\
\text { sovereign } \\
\text { debt }(\$ \text { bn }) \\
\end{array}$ & $\begin{array}{c}\text { Sovereign } \\
\text { downgrade } \\
\text { (notches) }\end{array}$ & $\begin{array}{c}\text { Cost of sovereign } \\
\text { borrowing }(\$ \text { bn) } \\
\text { (lower bound) }\end{array}$ & $\begin{array}{c}\text { Cost of sovereign } \\
\text { borrowing }(\$ \text { bn) } \\
\text { (higher bound) }\end{array}$ \\
\hline Albania & 6.50 & 1.31 & 0.01 & 0.01 \\
\hline Australia & 384.50 & 4.01 & 1.23 & 1.85 \\
\hline Austria & 231.70 & 2.26 & 0.42 & 0.63 \\
\hline Bangladesh & 45.50 & 1.57 & 0.06 & 0.09 \\
\hline Belgium & 436.90 & 2.53 & 0.88 & 1.32 \\
\hline Benin & 3.90 & 1.08 & 0.00 & 0.01 \\
\hline Bolivia & 4.90 & 0.69 & 0.00 & 0.00 \\
\hline Botswana & 1.10 & 3.33 & 0.00 & 0.00 \\
\hline Brazil & 1032.60 & 1.54 & 1.27 & 1.91 \\
\hline Bulgaria & 10.80 & 3.86 & 0.03 & 0.05 \\
\hline Canada & 557.10 & 5.15 & 2.30 & 3.45 \\
\hline Cape Verde & 1.30 & 0.45 & 0.00 & 0.00 \\
\hline Chile & 70.50 & 8.26 & 0.47 & 0.70 \\
\hline China & 2464.40 & 6.55 & 12.92 & 19.38 \\
\hline Colombia & 129.80 & 4.55 & 0.47 & 0.71 \\
\hline Costa Rica & 31.40 & 1.05 & 0.03 & 0.04 \\
\hline Croatia & 34.60 & 0.97 & 0.03 & 0.04 \\
\hline Cyprus & 13.80 & 0.12 & 0.00 & 0.00 \\
\hline Czechia & 70.20 & 2.81 & 0.16 & 0.24 \\
\hline $\begin{array}{l}\text { Denmark } \\
\text { Dominican }\end{array}$ & 91.70 & 3.49 & 0.26 & 0.38 \\
\hline Republic & 28.70 & 1.00 & 0.02 & 0.03 \\
\hline Estonia & 0.10 & 1.52 & 0.00 & 0.00 \\
\hline Fiji & 2.30 & 0.50 & 0.00 & 0.00 \\
\hline Finland & 118.10 & 1.75 & 0.17 & 0.25 \\
\hline France & 2026.10 & 2.43 & 3.93 & 5.90 \\
\hline Georgia & 2.60 & 1.62 & 0.00 & 0.01 \\
\hline Germany & 1254.30 & 3.65 & 3.66 & 5.49 \\
\hline Guatemala & 15.90 & 1.65 & 0.02 & 0.03 \\
\hline Honduras & 6.80 & 0.23 & 0.00 & 0.00 \\
\hline Hungary & 93.10 & 2.22 & 0.17 & 0.25 \\
\hline India & 1365.30 & 5.39 & 5.89 & 8.83 \\
\hline Indonesia & 290.60 & 3.96 & 0.92 & 1.38 \\
\hline Israel & 237.90 & 1.03 & 0.20 & 0.29 \\
\hline Italy & 2225.30 & 0.30 & 0.54 & 0.81 \\
\hline Japan & 10396.20 & 2.39 & 19.86 & 29.80 \\
\hline Jordan & 29.50 & 1.60 & 0.04 & 0.06 \\
\hline Kazakhstan & 26.80 & 4.92 & 0.11 & 0.16 \\
\hline
\end{tabular}




\begin{tabular}{|c|c|c|c|c|}
\hline \multicolumn{5}{|c|}{ Table D.2. Continued } \\
\hline Sovereign & $\begin{array}{c}\text { Outstanding } \\
\text { sovereign } \\
\text { debt }(\$ \text { bn) } \\
\end{array}$ & $\begin{array}{c}\text { Sovereign } \\
\text { downgrade } \\
\text { (notches) }\end{array}$ & $\begin{array}{c}\text { Cost of sovereign } \\
\text { borrowing }(\$ \text { bn) } \\
\text { (lower bound) }\end{array}$ & $\begin{array}{c}\text { Cost of sovereign } \\
\text { borrowing }(\$ \text { bn) } \\
\text { (higher bound) }\end{array}$ \\
\hline Kenya & 37.00 & 0.98 & 0.03 & 0.04 \\
\hline South Korea & 589.50 & 3.09 & 1.46 & 2.19 \\
\hline Kuwait & 16.50 & 0.88 & 0.01 & 0.02 \\
\hline Latvia & 11.20 & 3.10 & 0.03 & 0.04 \\
\hline Lithuania & 16.90 & 2.04 & 0.03 & 0.04 \\
\hline Luxembourg & 11.70 & 2.25 & 0.02 & 0.03 \\
\hline Malaysia & 189.80 & 5.80 & 0.88 & 1.32 \\
\hline Mexico & 386.40 & 5.52 & 1.71 & 2.56 \\
\hline Mongolia & 4.90 & 0.48 & 0.00 & 0.00 \\
\hline Morocco & 67.20 & 4.99 & 0.27 & 0.40 \\
\hline Netherlands & 341.40 & 3.32 & 0.91 & 1.36 \\
\hline New Zealand & 52.70 & 2.69 & 0.11 & 0.17 \\
\hline Macedonia & 4.00 & 2.15 & 0.01 & 0.01 \\
\hline Norway & 49.80 & 2.05 & 0.08 & 0.12 \\
\hline Oman & 40.60 & 0.06 & 0.00 & 0.00 \\
\hline Pakistan & 141.90 & 0.30 & 0.03 & 0.05 \\
\hline Panama & 23.60 & 3.83 & 0.07 & 0.11 \\
\hline Paraguay & 5.20 & 0.90 & 0.00 & 0.01 \\
\hline Peru & 49.10 & 5.32 & 0.21 & 0.31 \\
\hline Philippines & 134.50 & 3.69 & 0.40 & 0.60 \\
\hline Poland & 222.40 & 4.55 & 0.81 & 1.21 \\
\hline Portugal & 224.90 & 1.51 & 0.27 & 0.41 \\
\hline Qatar & 100.20 & 0.57 & 0.05 & 0.07 \\
\hline Romania & 88.90 & 3.13 & 0.22 & 0.33 \\
\hline Russia & 191.40 & 0.51 & 0.08 & 0.12 \\
\hline Rwanda & 1.40 & 0.58 & 0.00 & 0.00 \\
\hline Saudi Arabia & 167.50 & 0.33 & 0.04 & 0.07 \\
\hline Senegal & 6.00 & 0.91 & 0.00 & 0.01 \\
\hline Serbia & 14.30 & 2.07 & 0.02 & 0.04 \\
\hline Slovakia & 42.90 & 6.48 & 0.22 & 0.33 \\
\hline Slovenia & 31.00 & 3.66 & 0.09 & 0.14 \\
\hline South Africa & 213.30 & 3.13 & 0.53 & 0.80 \\
\hline Sri Lanka & 57.20 & 1.11 & 0.05 & 0.08 \\
\hline Suriname & 1.70 & 0.49 & 0.00 & 0.00 \\
\hline Sweden & 119.70 & 3.50 & 0.34 & 0.50 \\
\hline Switzerland & 68.60 & 3.11 & 0.17 & 0.26 \\
\hline Thailand & 180.20 & 2.31 & 0.33 & 0.50 \\
\hline Trinidad \& Tobago & 9.00 & 0.50 & 0.00 & 0.01 \\
\hline Turkey & 204.50 & 1.49 & 0.24 & 0.37 \\
\hline United Kingdom & 2710.70 & 3.48 & 7.54 & 11.31 \\
\hline United States & 16673.40 & 4.74 & 63.18 & 94.76 \\
\hline
\end{tabular}




\begin{tabular}{|c|c|c|c|c|}
\hline \multicolumn{5}{|c|}{ Table D.2. Continued } \\
\hline Sovereign & $\begin{array}{c}\text { Outstanding } \\
\text { sovereign } \\
\text { debt }(\$ \text { bn })\end{array}$ & $\begin{array}{c}\text { Sovereign } \\
\text { downgrade } \\
\text { (notches) }\end{array}$ & $\begin{array}{l}\text { Cost of sovereign } \\
\text { borrowing ( } \$ \text { bn) } \\
\text { (lower bound) }\end{array}$ & $\begin{array}{c}\text { Cost of sovereign } \\
\text { borrowing ( } \$ \text { bn) } \\
\text { (higher bound) }\end{array}$ \\
\hline Uruguay & 27.10 & 3.06 & 0.07 & 0.10 \\
\hline Vietnam & 53.70 & 2.14 & 0.09 & 0.14 \\
\hline Full sample total & 47326.70 & 2.48 & 136.68 & 205.02 \\
\hline
\end{tabular}

Notes: Translating climate-induced sovereign downgrades into increased sovereign cost of borrowing by 2100 under RCP 8.5 scenario. Dataset includes 80 downgraded sovereigns and their outstanding sovereign debt figures for 2019 obtained from S\&P SRIs. Conversion between sovereign downgrades into yields for lower bound is based on Afonso et al. (2012) and for higher bound on Gande \& Parsley (2005), whereby 1 notch sovereign downgrade increases sovereign bond spread by $0.08 \%$ and $0.12 \%$ respectively. 
Table D.3. Additional cost of corporate debt due to climate-induced sovereign downgrades (RCP 2.6, 2100)

\begin{tabular}{|c|c|c|c|c|}
\hline Sovereign & $\begin{array}{c}\text { Sovereign } \\
\text { downgrade } \\
\text { (notches) }\end{array}$ & $\begin{array}{c}\text { Outstanding } \\
\text { corporate debt } \\
(\$ \text { bn })\end{array}$ & $\begin{array}{c}\text { Increase in cost } \\
\text { of debt }(\$ \text { bn) } \\
\text { lower bound } \\
\end{array}$ & $\begin{array}{c}\text { Increase in cost } \\
\text { of debt ( } \$ \text { bn) } \\
\text { higher bound }\end{array}$ \\
\hline Australia & 1.09 & 213 & 0.11 & 0.20 \\
\hline Austria & 1.16 & 44 & 0.02 & 0.04 \\
\hline Belgium & 0.52 & 70 & 0.02 & 0.03 \\
\hline Bulgaria & 0.19 & 2 & 0.00 & 0.00 \\
\hline Canada & 0.58 & 515 & 0.14 & 0.25 \\
\hline Czechia & 0.73 & 15 & 0.01 & 0.01 \\
\hline Chile & 2.56 & 89 & 0.11 & 0.19 \\
\hline China & 2.05 & 4061 & 4.00 & 6.99 \\
\hline Denmark & 0.66 & 25 & 0.01 & 0.01 \\
\hline Estonia & 0.39 & 1 & 0.00 & 0.00 \\
\hline Finland & 0.48 & 39 & 0.01 & 0.02 \\
\hline France & 0.83 & 777 & 0.31 & 0.54 \\
\hline Germany & 0.23 & 241 & 0.03 & 0.05 \\
\hline Israel & 0.17 & 66 & 0.01 & 0.01 \\
\hline Japan & 0.36 & 845 & 0.15 & 0.26 \\
\hline Luxembourg & 0.11 & 30 & 0.00 & 0.00 \\
\hline Malaysia & 0.71 & 176 & 0.06 & 0.10 \\
\hline Netherlands & 0.37 & 180 & 0.03 & 0.06 \\
\hline Norway & 0.34 & 91 & 0.01 & 0.03 \\
\hline Peru & 1.11 & 21 & 0.01 & 0.02 \\
\hline Philippines & 0.73 & 14 & 0.00 & 0.01 \\
\hline Poland & 0.66 & 20 & 0.01 & 0.01 \\
\hline Slovakia & 0.89 & 5 & 0.00 & 0.00 \\
\hline Slovenia & 0.59 & 1 & 0.00 & 0.00 \\
\hline Sweden & 0.92 & 9 & 0.00 & 0.01 \\
\hline Thailand & 0.59 & 116 & 0.03 & 0.06 \\
\hline United Kingdom & 0.92 & 564 & 0.25 & 0.44 \\
\hline United States & 0.55 & 7126 & 1.88 & 3.29 \\
\hline Total BIS & 0.73 & 15356 & 7.21 & 12.62 \\
\hline
\end{tabular}

Notes: Translating climate-induced sovereign downgrades into increased corporate cost of debt by 2100 under RCP 2.6 scenario. Data availability from BIS on corporate debt restricts our sample to 28 countries. To calculate the value of corporate debt affected by sovereign downgrades we first convert the sovereign rating changes into sovereign yield which we then convert into corporate sovereign yield. To convert sovereign ratings into yields we use lower bond (0.08\%) from Afonso et al. (2012) and higher bound (0.12\%) from Gande \& Parsley (2005). To then translate these into corporate spreads we use Almeida et al. (2017)' conversions, with 0.6 for lower bound and 0.7 for higher bound. We multiply sovereign rating changes (see column 2 ) by an amount of outstanding debt at end-June 2020 (column 3) and 0.00048 for a lower bound $(0.08 \% * 0.6)$ and $0.00084(0.12 \% * 0.7)$ for a higher bound. 
Table D.4. Additional cost of corporate debt due to climate-induced sovereign downgrades (RCP 8.5, 2100)

\begin{tabular}{|c|c|c|c|c|}
\hline Sovereign & $\begin{array}{c}\begin{array}{c}\text { Sovereign } \\
\text { downgrade } \\
\text { (notches) }\end{array} \\
\end{array}$ & $\begin{array}{c}\begin{array}{c}\text { Outstanding } \\
\text { corporate debt } \\
(\$ \text { bn })\end{array} \\
\end{array}$ & $\begin{array}{c}\text { Increase in cost } \\
\text { of debt }(\$ \text { bn) } \\
\text { lower bound }\end{array}$ & $\begin{array}{c}\text { Increase in cost } \\
\text { of debt }(\$ \text { bn) } \\
\text { higher bound }\end{array}$ \\
\hline Australia & 4.01 & 213 & 0.41 & 0.72 \\
\hline Austria & 2.26 & 44 & 0.05 & 0.08 \\
\hline Belgium & 2.53 & 70 & 0.09 & 0.15 \\
\hline Bulgaria & 3.86 & 2 & 0.00 & 0.01 \\
\hline Canada & 5.15 & 515 & 1.27 & 2.23 \\
\hline Czechia & 2.81 & 15 & 0.02 & 0.04 \\
\hline Chile & 8.26 & 89 & 0.35 & 0.62 \\
\hline China & 6.55 & 4061 & 12.77 & 22.34 \\
\hline Croatia & 0.97 & 3 & 0.00 & 0.00 \\
\hline Denmark & 3.49 & 25 & 0.04 & 0.07 \\
\hline Estonia & 1.52 & 1 & 0.00 & 0.00 \\
\hline Finland & 1.75 & 39 & 0.03 & 0.06 \\
\hline France & 2.43 & 777 & 0.91 & 1.59 \\
\hline Germany & 3.65 & 241 & 0.42 & 0.74 \\
\hline Hungary & 2.22 & 3 & 0.00 & 0.01 \\
\hline Israel & 1.03 & 66 & 0.03 & 0.06 \\
\hline Italy & 0.3 & 152 & 0.02 & 0.04 \\
\hline Japan & 2.39 & 845 & 0.97 & 1.70 \\
\hline Lithuania & 2.04 & 1 & 0.00 & 0.00 \\
\hline Luxembourg & 2.25 & 30 & 0.03 & 0.06 \\
\hline Malaysia & 5.8 & 176 & 0.49 & 0.86 \\
\hline Netherlands & 3.32 & 180 & 0.29 & 0.50 \\
\hline Norway & 2.05 & 91 & 0.09 & 0.16 \\
\hline Peru & 5.32 & 21 & 0.05 & 0.09 \\
\hline Philippines & 3.69 & 14 & 0.02 & 0.04 \\
\hline Poland & 4.55 & 20 & 0.04 & 0.08 \\
\hline Portugal & 1.51 & 37 & 0.03 & 0.05 \\
\hline Slovakia & 6.48 & 5 & 0.02 & 0.03 \\
\hline Slovenia & 3.66 & 1 & 0.00 & 0.00 \\
\hline Sweden & 3.5 & 9 & 0.02 & 0.03 \\
\hline Thailand & 2.31 & 116 & 0.13 & 0.23 \\
\hline Turkey & 1.49 & 9 & 0.01 & 0.01 \\
\hline United Kingdom & 3.48 & 564 & 0.94 & 1.65 \\
\hline United States & 4.74 & 7126 & 16.21 & 28.37 \\
\hline Total BIS & 3.28 & 15561 & 35.76 & 62.59 \\
\hline
\end{tabular}

Notes: Translating climate-induced sovereign downgrades into increased corporate cost of debt by 2100 under RCP 8.5 scenario. Data availability from BIS on corporate debt restricts our sample to 34 countries. To calculate the value of corporate debt affected by sovereign downgrades we first convert the sovereign rating changes into sovereign yield which we then convert into corporate sovereign yield. To convert sovereign ratings into yields we use lower bond (0.08\%) from Afonso et al. (2012) and higher bound (0.12\%) from Gande \& Parsley (2005). To then translate these into corporate spreads we use Almeida et al. (2017)' conversions, with 0.6 for lower bound and 0.7 for higher bound. We multiply sovereign rating changes (see column 2) by an amount of outstanding debt at end-June 2020 (column 3) and 0.00048 for a lower bound $(0.08 \% * 0.6)$ and $0.00084(0.12 \% * 0.7)$ for a higher bound. 


\section{IMFS WORKING PAPER SERIES}

\section{Recent Issues}

\begin{tabular}{|c|c|c|}
\hline 157 / 2021 & $\begin{array}{l}\text { Yvan Lengwiler } \\
\text { Athanasios Orphanides }\end{array}$ & $\begin{array}{l}\text { Collateral Framework:Liquidity Premia } \\
\text { and Multiple Equilibria }\end{array}$ \\
\hline $156 / 2021$ & $\begin{array}{l}\text { Gregor Boehl } \\
\text { Cars Hommes }\end{array}$ & $\begin{array}{l}\text { Rational vs. Irrational Beliefs in a Complex } \\
\text { World }\end{array}$ \\
\hline 155 / 2021 & $\begin{array}{l}\text { Michael D. Bauer } \\
\text { Eric T. Swanson }\end{array}$ & $\begin{array}{l}\text { The Fed's Response to Economic News } \\
\text { Explains the "Fed Information Effect" }\end{array}$ \\
\hline 154 / 2021 & Alexander Meyer-Gohde & $\begin{array}{l}\text { On the Accuracy of Linear DSGE Solution } \\
\text { Methods and the Consequences for Log- } \\
\text { Normal Asset Pricing }\end{array}$ \\
\hline $153 / 2021$ & $\begin{array}{l}\text { Gregor Boehl } \\
\text { Philipp Lieberknecht }\end{array}$ & $\begin{array}{l}\text { The Hockey Stick Phillips Curve and the } \\
\text { Zero Lower Bound }\end{array}$ \\
\hline 152 / 2021 & $\begin{array}{l}\text { Lazar Milivojevic } \\
\text { Balint Tatar }\end{array}$ & $\begin{array}{l}\text { Fixed exchange rate - a friend or foe of } \\
\text { labor cost adjustments? }\end{array}$ \\
\hline $151 / 2021$ & $\begin{array}{l}\text { Thomas Jost } \\
\text { Franz Seitz }\end{array}$ & $\begin{array}{l}\text { Designing a European Monetary Fund: } \\
\text { What role for the IMF? }\end{array}$ \\
\hline $150 / 2021$ & $\begin{array}{l}\text { Gerhard Rösl } \\
\text { Franz Seitz }\end{array}$ & $\begin{array}{l}\text { Cash and Crises: No surprises by the } \\
\text { virus }\end{array}$ \\
\hline 149 / 2021 & $\begin{array}{l}\text { Wolfgang Lechthaler } \\
\text { Mewael F. Tesfaselassie }\end{array}$ & $\begin{array}{l}\text { Endogenous Growth, Skill Obsolescence } \\
\text { and Output Hysteresis in a New } \\
\text { Keynesian Model with Unemployment }\end{array}$ \\
\hline $148 / 2021$ & Gregor Boehl & $\begin{array}{l}\text { Efficient Solution and Computation of } \\
\text { Models with Occasionally Binding } \\
\text { Constraints }\end{array}$ \\
\hline 147 / 2021 & $\begin{array}{l}\text { Brian Fabo } \\
\text { Martina Jančoková } \\
\text { Elisabeth Kempf } \\
\text { Luboš Pástor }\end{array}$ & $\begin{array}{l}\text { Fifty Shades of QE: Conflicts of Interest in } \\
\text { Economic Research }\end{array}$ \\
\hline $146 / 2021$ & $\begin{array}{l}\text { Robert C.M. Beyer } \\
\text { Lazar Milivojevic }\end{array}$ & $\begin{array}{l}\text { Dynamics and Synchronization of Global } \\
\text { Equilibrium Interest Rates }\end{array}$ \\
\hline 145 / 2020 & $\begin{array}{l}\text { Lars P. Feld } \\
\text { Volker Wieland }\end{array}$ & $\begin{array}{l}\text { The German Federal Constitutional Court } \\
\text { Ruling and the European Central Bank's } \\
\text { Strategy }\end{array}$ \\
\hline 144 / 2020 & $\begin{array}{l}\text { Mátyás Farkas } \\
\text { Balint Tatar }\end{array}$ & $\begin{array}{l}\text { Bayesian Estimation of DSGE Models } \\
\text { with Hamiltonian Monte Carlo }\end{array}$ \\
\hline $143 / 2020$ & $\begin{array}{l}\text { Gregor Boehl } \\
\text { Felix Strobel }\end{array}$ & $\begin{array}{l}\text { U.S. Business Cycle Dynamics at the } \\
\text { Zero Lower Bound }\end{array}$ \\
\hline
\end{tabular}




\begin{tabular}{|c|c|c|}
\hline $142 / 2020$ & $\begin{array}{l}\text { Gregor Boehl } \\
\text { Gavin Goy } \\
\text { Felix Strobel }\end{array}$ & $\begin{array}{l}\text { A Structural Investigation of Quantitative } \\
\text { Easing }\end{array}$ \\
\hline $141 / 2020$ & Karl-Heinz Tödter & $\begin{array}{l}\text { Ein SIRD-Modell zur Infektionsdynamik } \\
\text { mit endogener Behandlungskapazität und } \\
\text { Lehren für Corona-Statistiken }\end{array}$ \\
\hline $140 / 2020$ & $\begin{array}{l}\text { Helmut Siekmann } \\
\text { Volker Wieland }\end{array}$ & $\begin{array}{l}\text { The Ruling of the Federal Constitutional } \\
\text { Court concerning the Public Sector } \\
\text { Purchase Program: A Practical Way } \\
\text { Forward }\end{array}$ \\
\hline $139 / 2020$ & Volker Wieland & $\begin{array}{l}\text { Verfahren zum Anleihekaufprogramm der } \\
\text { EZB }\end{array}$ \\
\hline $138 / 2020$ & $\begin{array}{l}\text { Francisco Gomes } \\
\text { Michael Haliassos } \\
\text { Tarun Ramadorai }\end{array}$ & Household Finance \\
\hline $137 / 2019$ & $\begin{array}{l}\text { Martin Kliem } \\
\text { Alexander Meyer-Gohde }\end{array}$ & $\begin{array}{l}\text { (Un)expected Monetary Policy Shocks } \\
\text { and Term Premia }\end{array}$ \\
\hline $136 / 2019$ & $\begin{array}{l}\text { Luc Arrondel } \\
\text { Hector Calvo-Pardo } \\
\text { Chryssi Giannitsarou } \\
\text { Michael Haliassos }\end{array}$ & Informative Social Interactions \\
\hline $135 / 2019$ & $\begin{array}{l}\text { Tiziana Assenza } \\
\text { Alberto Cardaci } \\
\text { Domenico Delli Gatti }\end{array}$ & $\begin{array}{l}\text { Perceived wealth, cognitive sophistication } \\
\text { and behavioral inattention }\end{array}$ \\
\hline $134 / 2019$ & Helmut Siekmann & $\begin{array}{l}\text { The Asset Purchase Programmes of the } \\
\text { ESCB - an interdisciplinary evaluation }\end{array}$ \\
\hline $133 / 2019$ & $\begin{array}{l}\text { Josefine Quast } \\
\text { Maik Wolters }\end{array}$ & $\begin{array}{l}\text { Reliable Real-time Output Gap Estimates } \\
\text { Based on a Modified Hamilton Filter }\end{array}$ \\
\hline $132 / 2019$ & $\begin{array}{l}\text { Galina Potjagailo } \\
\text { Maik Wolters }\end{array}$ & Global Financial Cycles since 1880 \\
\hline $131 / 2019$ & $\begin{array}{l}\text { Philipp Lieberknecht } \\
\text { Volker Wieland }\end{array}$ & $\begin{array}{l}\text { On the Macroeconomic and Fiscal Effects } \\
\text { of the Tax Cuts and Jobs Act }\end{array}$ \\
\hline $130 / 2019$ & Eduard Hofert & Regulating Virtual Currencies \\
\hline $129 / 2018$ & $\begin{array}{l}\text { Olga Goldfayn-Frank } \\
\text { Johannes Wohlfart }\end{array}$ & $\begin{array}{l}\text { How Do Consumers Adapt to a New } \\
\text { Environment in their Economic } \\
\text { Forecasting? Evidence from the German } \\
\text { Reunification }\end{array}$ \\
\hline $128 / 2018$ & $\begin{array}{l}\text { Christopher Roth } \\
\text { Johannes Wohlfart }\end{array}$ & $\begin{array}{l}\text { How Do Expectations About the } \\
\text { Macroeconomy Affect Personal } \\
\text { Expectations and Behavior? }\end{array}$ \\
\hline $127 / 2018$ & $\begin{array}{l}\text { Michael Haliassos } \\
\text { Thomas Jansson } \\
\text { Yigitcan Karabulut }\end{array}$ & Financial Literacy Externalities \\
\hline
\end{tabular}

